\title{
High-Heat-Load Studies of Silicon and Diamond Monochromators Using the APS/CHESS Prototype Undulator
}

\section{M. Mills, W.-K. Lee, R. K. Smither, and P. B. Fernandez Experimental Facilities Division}

\section{DISCLAIMER}

This report was prepared as an account of work sponsored by an agency of the United States Government. Neither the United States Government nor any agency thereof, nor any of their employees, makes any warranty, express or implied, or assumes any legal liability or responsibility for the accuracy, completeness, or usefulness of any information, apparatus, product, or process disclosed, or represents that its use would not infringe privately owned rights. Reference herein to any specific commercial product, process, or service by trade name, trademark, manufacturer, or otherwise does not necessarily constitute or imply its endorsement, recommendation, or favoring by the United States Government or any agency thereof. The views and opinions of authors expressed herein do not necessarily state or reflect those of the United States Government or any agency thereof.

September 16, 1994

\section{Advanced Photon Source Argonne National Laboratory}




\section{DISCLAIMER}

Portions of this document may be illegible in electronic image products. Images are produced from the best available original document. 


\title{
High-Heat-Load Studies of Silicon and Diamond Monochromators Using the APS/CHESS Prototype Undulator
}

\author{
D.M. Mills, W.-K. Lee, R.K. Smither and P. B. Fernandez \\ Advanced Photon Source \\ Argonne National Laboratory \\ 9700 S. Cass Avenue \\ Argonne, IL 60439
}

\begin{abstract}
The results of the latest high-heat-load studies made on the APS/CHESS prototype undulator are summarized. Four different crystals were tested: two slotted, symmetrically cut silicon crystals and a coredrilled, asymmetrically cut silicon crystal (which were gallium cooled), and a diamond crystal that was jet cooled using water. The purpose of the silicon crystal tests was to reevaluate the surface power loading at which appreciable degradation of the diffraction efficiency was observed. The diamond tests, allotted only a brief period of time during the testing period, were our first attempt at using diamonds for high-heat-flux x-ray monochromators and were performed primarily to gain first-hand experience with diamond monochromators. Measurements with the silicon crystal at $5 \mathrm{keV}$ reconfirmed our previous measurements of performance degradation at around 4-6 watts $/ \mathrm{mm}^{2}$ using liquid gallium with slotted coolant channels. A value of only 2 watts $/ \mathrm{mm}^{2}$ was observed to cause a degradation of the diffraction performance at $15 \mathrm{keV}$ with the same crystals due to the increased sensitivity to strain because of the reduced Darwin widths. The performance of the asymmetric crystal, with its core-drilled coolant channels, was not found to be as good as that of the slotted crystals. This was probably due to poorer heat transfer properties of the core-drilled geometry in combination with the narrowing of the rocking curves because of the asymmetric cut. Fabrication issues for construction of the gallium-cooled crystals is also discussed.

Although the diamonds were only successfully tested at low total power (17 watts total incident power, 25 $\mathrm{w} / \mathrm{mm}^{2}$ incident power density), the results were very encouraging and motivated us to accelerate our program on the use of diamonds for high-heat-load monochromators.
\end{abstract}




\section{Introduction}

In October 1993, the APS/CHESS undulator was installed on the Cornell Electron-Positron Storage Ring (CESR) with the storage ring operating in a dedicated, low-emittance mode. Under these conditions, the radiation emitted from the APS/CHESS prototype insertion device simulated, to some extent, the type of radiation expected from the Advanced Photon Source (APS). The first week of operation of the undulator was dedicated to diagnostics of the machine, radiation, and performance testing or evaluation of several different silicon monochromators and one diamond monochromator. The primary purpose of the silicon crystal experiments was to determine the surface power density at which appreciable degradation in the diffraction performance is observed for a given geometry and (liquid gallium) coolant flow rate. The diamond monochromator experiment, allotted only a brief period of time in our testing program, was our first attempt at using diamond as a monochromating crystal. Experiments were performed primarily to gain first-hand experience in this relatively new field of using single-crystal diamonds as first optical components in high-power-density $\mathrm{x}$-ray beams.

\section{The Source}

The APS/CHESS prototype undulator has been described in detail elsewhere, 1 and only a brief summary of its relevant parameters is given in Table $\mathrm{I}$.

\section{Table I}

\begin{tabular}{ll} 
Parameter & Value \\
\hline Period $\lambda \mathrm{u}(\mathrm{cm})$ & 3.3 \\
Length $\mathrm{L}(\mathrm{m})$ & 2.03 \\
No. of poles & 123 \\
$\mathrm{~K}\left(=0.934 \lambda \mathrm{u}(\mathrm{cm}) \mathrm{B}_{\mathrm{o}}(\mathrm{T})\right)$ & \\
$\quad$ closed gap $(13.5 \mathrm{~mm})$ & 1.6 \\
$\quad$ open gap $(30.0 \mathrm{~mm})$ & 0.4 \\
\hline
\end{tabular}

During dedicated running for the undulator, CESR was operated at $5.43 \mathrm{GeV}$ and up to $100 \mathrm{~mA}$. Given these parameters, the radiation emitted from the undulator has the properties given in Table II below. 


\section{Table II}

\begin{tabular}{ll} 
Parameter & Value \\
1st harmonic (keV) & \\
closed gap $(13.5 \mathrm{~mm})$ & 3.7 \\
open gap (30.0 mm) & 7.9 \\
Total power (watts) & \\
closed gap (13.5 mm) & 1024 \\
open gap (30.0 mm) & 64 \\
\hline
\end{tabular}

The calculated horizontal and vertical emittances for this lattice were $6.5 \times 10^{-8} \mathrm{~m}$-rad and $1.0 \times 10^{-9} \mathrm{~m}$-rad, respectively, with a horizontal beta of $19.48 \mathrm{~m}$ and a vertical beta of $4.89 \mathrm{~m}$ at the location of the undulator. ${ }^{2}$

\section{Experimental Layout}

Between our test optics, located $20 \mathrm{~m}$ from the source, and the source itself was a total of $250 \mu$ of carbon and $1 \mathrm{~mm}$ of beryllium (250- $\mu$ carbon filter followed by two $250-\mu$ beryllium front-end windows, two $125-\mu$ windows on the split ion chamber, and one $250-\mu$ beryllium window at the end of the beamline - see Fig. 1 for a schematic layout of the experiment). Our calculations show that the absorption from the $\mathrm{Be}$ and $\mathrm{C}$ reduced the power and power density at our crystals from 519 watts to 289 watts when operating at a $\mathrm{K}$ value of 1.14 (first harmonic at $5.15 \mathrm{keV}$ ) and $100 \mathrm{~mA}$. Figure 2 shows the raw spectral distribution and the spectral distribution after the Be filters and windows from the undulator at $\mathrm{K}=1.14$. Calorimetry of the beam was also performed to measure the total power incident on the crystal. We used copper calorimeters of several sizes and shapes to measure the total power in the beam. Using a 641-gm copper calorimeter, several measurements were made resulting in a measured total power of from 316 to 347 watts at 100 milliampere beam current. Note that all of these measurements are higher than the calculated power transmitted through the filters and windows of 289 watts. At this point, the source of this difference is not known however perhaps the densities or thicknesses of the foils were not as presumed.

The white-beam size was measured by W. Yun and colleagues from APS at 27 meters from the source with the undulator operating at a $\mathrm{K}$ value of 0.5 . From these measurements, we have worked backwards to estimate the beam size at 20 meters and with a $\mathrm{K}$ value of 1.14 . The extrapolated values at 20 meters were 0.9 
$\mathrm{mm}$ vertical and $2.2 \mathrm{~mm}$ horizontal (all values given are 1 sigma values). These numbers should be compared to the calculated sizes at 20 meters (using the calculated emittances and beta functions) of $1.2 \mathrm{~mm}$ vertical and 2.2 $\mathrm{mm}$ horizontal. Given the uncertainty in our measurements, we have estimated our peak power density for $\mathrm{K}=$ 1.14 to be in the range of $\approx 25$ watts $/ \mathrm{mm}^{2}$ at $100 \mathrm{~mA}$ operation with an error of $\pm 2-4$ watts $/ \mathrm{mm}^{2}$. Throughout the remainder of this report we will assume a peak power density of 25 watts $/ \mathrm{mm}^{2}$ at $100 \mathrm{~mA}$ operation with $\mathrm{K}=$ 1.14 .

The monochromator tests were performed in the CHESS A3 Station. The tests were performed in a box under a He environment (at one atmosphere) to reduce the ozone production from the white beam. However, because the box was not vacuum tight, it could not be pumped out, and we found on several occasions that our count rates in the detectors were sensitive to the flow rate of $\mathrm{He}$ into the box and/or inadequate purging of the box. (This phenomena was particularly true when runs were made at $5 \mathrm{keV}$ at which energy air absorption can be appreciable.) Therefore direct comparison of the intensities measured from one run to the next are not to be trusted, particularly those intensities taken at low $\mathrm{x}$-ray energies. All rocking curve measurements were collected by scanning the Bragg angle of the second crystal which was under computer control via a step-motor (minimum step size 0.9 arc seconds). The second crystal also had a piezoelectric transducer actuating a lever arm for fine Bragg angle adjustments. Since these two Bragg angle adjustments are independent of one another, angle measurements based solely on the step motor position will not be consistent.

\section{Fabrication Difficulties with Slotted Silicon Crystals}

Two slotted silicon crystals of almost identical designs, but bonded using different techniques, were tested. The crystals were fabricated with the diffracting surfaces cut parallel to the (111) atomic planes. A schematic of the crystals with the important dimensions can be found in Figure 3. All tests were made in the "standard" geometry (i.e., not inclined) so that the surfaces would be subjected to as large a power density as possible. Runs were made using the undulator first harmonic of $\approx 5 \mathrm{keV}$ diffracting from the (111) planes or from the third harmonic at $\approx 15 \mathrm{keV}$ diffracting from the (111) planes to provide high power density from the small gap required to produce these energies. Runs were also made at $7.5 \mathrm{keV}$ because this energy was of interest for experiments that were to follow the crystal-heating tests. Before describing the thermal responses of these 
crystals, a comment on crystal bonding is necessary. Our original plan called for the testing of a slotted crystal that was frit bonded, 3 a bonding technique that we have found to be compatible with liquid gallium. Unfortunately, that crystal was damaged during installation and checkout of the liquid gallium pump at CHESS. Hence, we were forced to rely on two back-up crystals, one that had been bonded with die-attach paste ${ }^{4}$ (a process we knew from past experience was not compatible with exposure to liquid gallium for extended periods of time) and another bonded with epoxy ${ }^{5}$ (with which we had only short-term experience with as far as gallium compatibility).

As was observed on previous runs using die-attach-paste-bonded crystals, a broadening of the rocking curve could be induced by increasing the coolant pressure. We have attributed this broadening to the paste being weakened or dissolved between the fins and the silicon substrate allowing the slotted area of the crystal to lift away from the substrate and bowing under the influence of the pressure exerted by the coolant. Because liquid gallium has a very small vapor pressure, it is possible to draw a vacuum on the coolant loop and to some extent compensate for the head pressure of the coolant. The results of such an experiment and the influence of the pumphead pressure are shown in Figure 4. In this figure, the open circles show the full width at half maximum (FWHM) of the rocking curves taken at various flow rates (and hence pump-head pressures) under low power loading conditions (approximately $10 \mathrm{~mA}$ stored current). The measurements were performed at $15 \mathrm{keV}$ where the theoretical rocking curve width is 5.0 arc seconds. At low flow rates, thermal broadening is observed. As the flow rate is increased, a reduction in the rocking curve FWHM can be seen due to an improved cooling capacity. A minimum occurs at about $1.5 \mathrm{gpm}$, at which point the vacuum drawn on the coolant loop somewhat compensates for the coolant head pressure while the flow rate is sufficient to adequately cool the crystal. At higher flow rates, even though the cooling capabilities are improving, a sharp increase is observed in the FWHM due to the increased head pressure of the coolant. To verify that this minimum in the FWHM vs. flow rate plot was related to the vacuum drawn on the coolant loop, the vacuum was reduced from 14.7 psi pressure to +10 psia. The rocking curve FWHM under these operating conditions is indicated by the solid circle. Also plotted, in open squares, is the ionization chamber current (Io) normalized by the current in the storage ring (Icesr) as a function of gallium flow. Not surprisingly, a maximum in that ratio occurs when the rocking curve is narrowest. 
Based on this data, all subsequent measurements made with the die-attach-paste-bonded crystals were made at a $1.5 \mathrm{gpm}$ gallium flow rate with a vacuum drawn on the coolant loop.

After only one day of flowing liquid gallium through the crystal (during which time the $5 \mathrm{keV}$ and $15 \mathrm{keV}$ data were collected), the energy was changed to $7.5 \mathrm{keV}$, and the normalized intensity as a function of gallium flow rate was measured (see Fig. 5). As before, a vacuum was drawn on the coolant loop during the measurements. These data were taken at a high power loading ( $90 \mathrm{~mA}$ stored current) and rocking curve FWHMs were not recorded therefore a direct comparison with the previous data cannot be made. Nonetheless, it is easy to see that the trend here is completely different than that from the data taken the day before. We take this monotonic decrease of intensity as the flow rate is increased as an indication that the bond had further weakened, and, as the pressure is increased, the rocking curve broadens and the intensity continuously decreases. At this point, no further data were collected with this crystal. We are currently looking into other types of die-attach pastes for bonding silicon to silicon. This particular paste has a sizable silver content (for increased thermal conductivity), and gallium is known to alloy with silver. Hence our search has focused on die-attach-paste compounds with little or no metal content.

The response of the epoxy-bonded crystal gave a monotonic increase in the normalized diffracted intensity (Io/Icesr) as a function of coolant flow rate (see Figure 6). These data, taken at $7.5 \mathrm{keV}$ with low power (12 mA stored beam current), indicate that the pressure from the coolant was not causing the crystal to distort substantially. (Rocking curves were not collected here and so FWHM values as a function of flow rate are not available.) Another measurement of the normalized intensity as a function of flow rate was taken several (4 1/2) days later, this time at $15 \mathrm{keV}$ but at much higher power (100 $\mathrm{mA})$. Under these conditions, a maximum in the intensity as a function of flow rate was observed (see Figure 7) similar to that previously observed with the dieattach-bonded crystal. The open data points in Figure 7 represent data collected with a vacuum drawn on the coolant line. As before, the gallium flow rate was adjusted to the value giving the maximum intensity, and additional pressure of 25 psi was applied to the coolant loop. The resulting intensity, indicated by the solid data point, clearly shows a reduction from the vacuum case. However the effect was not as large as was observed with the die-attached-bonded crystal assembly. Figure 8 shows the two rocking curves taken with the epoxybonded crystal with a gallium flow rate of $1.5 \mathrm{gpm}$ with (a) a vacuum drawn and with (b) 25 psi applied on the 
coolant loop. Although from these data it may appear that the epoxy bond is weakening, we cannot definitely draw that conclusion. The reasons for our hesitancy is: 1) we have observed no weakening of the epoxy due to exposure to gallium in the laboratory (albeit a short-term experiment) and 2) when operating at $15 \mathrm{keV}$ the beam is spread over a much larger region of the crystal. If a portion of the beam footprint was (inadvertently) over one of the distribution plenums during the tests, then a pressure effect could have easily been observed because there is no substrate to bond to over the plenum and bowing over the plenum region of the crystal under coolant pressure would not be surprising. We plan to look into this problem in more detail in the future with an in-house topography system, which we are now constructing.

\section{Thermal Response of the Slotted Crystals}

As mentioned previously, experiments were carried out primarily with 5 or $15 \mathrm{keV}$ x-rays diffracting from symmetrically cut $\mathrm{Si}(111)$ crystals with a gallium flow rate of $1.5 \mathrm{gpm}$. Figure 9 shows the measured intensity and rocking curve FWHM as a function of stored beam current at $5 \mathrm{keV}$ for the die-attach-bonded crystal. The complete set of rocking curves for this measurement is shown in Figure 10. The measured FWHM at low currents was about 17.5 arc seconds, slightly greater than the calculated value of 16 arc seconds. In the $5 \mathrm{keV}$ run, a 10\% deviation from the expected intensity (i.e., the intensity extrapolated from the low current data) occurred at about $40 \mathrm{~mA}$ of beam current. This current value corresponds to a power density on the crystal surface of 3.9 watts $/ \mathrm{mm}^{2}$, using our measured normal incidence value of 25 watts $/ \mathrm{mm}^{2}$.

Plots similar to those described above for data collected at $15 \mathrm{keV}$ taken with the die-attach-bonded crystal are shown in Figures 11 and 12. Again, the measured FWHM of the rocking curve at low current values was larger than that calculated from theory, 6.4 arc seconds as compared to 5 arc seconds. Using $15 \mathrm{keV} \mathrm{x}$-rays, the point at which a $10 \%$ deviation from the expected intensity occurred was $55 \mathrm{~mA}$. This corresponds to a surface power density of 1.8 watts $/ \mathrm{mm}^{2}$, lower than that of the $5-\mathrm{keV}$ data due to the increased sensitivity to strains because of the narrowing of the $\mathrm{Si}$ (111) Darwin width when going from 5 to $15 \mathrm{keV}$.

Careful comparison of Figures 10 and 12 will reveal that the direction of the rocking curve shift as a function of beam current goes in opposite directions in the two cases. We believe that all these shifts are artifacts, such as repositioning of the PZT transducer to center the scan, and not an indication of lattice expansion. 
Thermal tests comparable to those described above were made on an epoxy-bonded crystal assembly at 5 and $15 \mathrm{keV}(\mathrm{K}=1.14)$ and at $7.5 \mathrm{keV}(\mathrm{K}=0.5)$. We will discuss only the data for the higher $\mathrm{K}$ value, because the total power and power densities at the lower $\mathrm{K}$ value were considerably less. As before, these data were collected with a gallium flow rate of $1.5 \mathrm{gpm}$ and a vacuum drawn on the coolant loop. Figure 13 shows the intensity and rocking curve FWHM as a function of stored beam current measured at $5 \mathrm{keV}$. The measured FWHM at low currents for this crystal was 16.5 arc seconds, close to the theoretical value of 16 arc seconds. The $10 \%$ loss point for this run occurred at $50 \mathrm{~mA}$ or a surface power loading of 4.9 watts $/ \mathrm{mm}^{2}$, a value slightly higher than that of the die-attach-paste-bonded crystal. This is interesting since the faceplate of the epoxy-bonded crystal was 0.8 $\mathrm{mm}$, while that of the die-attach-pasted-bonded crystal was $1.0 \mathrm{~mm}$. The trend of improved performance with a thinner faceplate is certainly consistent with our heat transfer calculations. The complete set of rocking curves measured as a function of current is shown in Figure 14. Figures 15 and 16 show the same data collected at 3 gpm gallium flow. The $10 \%$ loss point is clearly shifted to higher values than the $1.5 \mathrm{gpm}$ data (approximately 65 $\mathrm{mA}$ or 6.4 watts $/ \mathrm{mm}^{2}$ ), however the FWHMs of the rocking curves are broader at $3 \mathrm{gpm}$, even at low current values, indicating that the coolant pressure broadening may be affecting this measurement. Hence quantitative comparisons between these two runs is difficult; however, qualitatively, a higher gallium flow rate seems to improve performance.

Figures 17 and 18 show the same types of plots taken at $15 \mathrm{keV}$ with $1.5 \mathrm{gpm}$ gallium flow. The intensity data in Figure 17 display an almost linear response as a function of beam current with little change in the FWHM of the rocking curve. Again, the measured low current FWHM value of 7.3 arc seconds is considerably broader than the theoretical value of 5 arc seconds; whereas for the $5 \mathrm{keV}$ data, the measured and theoretical values are much closer. The origin of this difference could arise from a variety of sources. As mentioned earlier, this could indicate that the bond between the fins and the substrate may be degrading or that, at these lower Bragg angles where the $\mathrm{x}$-rays illuminate a larger area of the crystal surface, we have inadvertently positioned the beam over one of the distribution plenums or we are simply sampling a larger part of a bowed crystal. Hence, although the intensity data look very good, quantitative interpretations are difficult because the crystal may never have diffracted with the efficiency of a perfect, unstrained crystal. 
During much of the data collection time, the surface temperatures of the crystals were monitored with an infrared camera and stored on a video recorder. Thus, the temperature information can be acquired in a noncontact way. However, due to the transparency of silicon to radiation in the $\mathbb{R}$ region and a nonideal emissivity, absolute temperatures are difficult to extract. Nonetheless, the IR images provide valuable comparisons of the thermal response of the crystal under varying heat loads and coolant flows. Figure 19 shows the change in the peak surface temperature taken directly from the video tape (i.e., no corrections were made) for the epoxy-bonded crystal at $5 \mathrm{keV}$ with 1.5 and 3.0 gpm gallium flows. Plotted in Figure 20 is the change in the peak surface temperature as a function of machine current for 5 and $15 \mathrm{keV}$ for the same crystal with a gallium flow of 1.5 gpm. Recall that the total power and peak power density coming from the undulator is the same in both cases; the only difference arises from the spreading of the incident beam on the surface of the crystal due to the difference in the Bragg angle for the 5- and 15-keV cases. The reduction of power density on the surface of the crystal of about a factor of three when going from 5 to $15 \mathrm{keV}$ is about the same size as the reduction in the peak surface temperature when going from high to low angles. Figure 21 shows the maximum surface temperature difference across the face of the epoxy-bonded crystal (at a Bragg angle of $23.4^{\circ}$ ) as a function of liquid-gallium flow rate for a stored beam current of near 100 milliamperes.

\section{Asymmetric-Cut/Cored-Drilled Silicon Crystal Tests}

An asymmetrically cut crystal (with $\alpha$, the miscut between the crystal surface and (111) planes, equal to $\left.5^{\circ}\right)$ was fabricated not with slots but rather with core-drilled coolant passages that were drilled perpendicular to the

plane of diffraction. A schematic of the crystal showing all the relevant dimensions is shown in Figure 22. Coredrilled coolant channels have the advantage that no bonding is required to seal the channels, but seals must still be made between the crystal and the coolant manifold. If water were to be used as the coolant, indium o-rings would perform adequately because they seal well and are not affected by the high doses of radiation that are prevalent. However, gallium dissolves indium easily, and so, for our tests, neoprene gaskets were used. We have found that these seals harden in the high radiation field and quickly loose their resiliency but nonetheless provide an adequate seal for the gallium, partially due to the high surface tension of liquid gallium. As with the slotted crystals, we tested the asymmetrically cut crystal at two energies 5 and $15 \mathrm{keV}$. The corresponding asymmetry 
factors, $|\mathrm{b}|[=\sin (\Theta-\alpha) / \sin (\Theta+\alpha)]$, for these two energies were 0.658 and 0.201 , respectively, two energies $x 2$. The asymmetric crystals were arranged such that the beam was incident on the first crystal at a more glancing angle over that of the symmetrically cut crystal. In this configuration, the rocking curve width for two asymmetric crystals should be reduced over that of two symmetric crystals by $V|\mathrm{~b}|$, namely by 0.81 at $5 \mathrm{keV}$ and by 0.45 at $15 \mathrm{keV}$.

When operated at $5 \mathrm{keV}$, the current value at which a $10 \%$ loss was recorded was approximately $31 \mathrm{~mA}$ (see Figure 23) corresponding to a surface power density of 2.4 watts $/ \mathrm{mm}^{2}$ with a $2 \mathrm{gpm}$ gallium flow. At the lowest current value, the measured value of the rocking curve, 13 arc seconds, is in excellent agreement with the theoretical value ( 15 arc sec. $x 0.81$ or 12.8 arc secs) indicating that fabrication and mounting strains were minimal. Data for the asymmetric, cored-drilled crystal at $15 \mathrm{keV}$ are plotted in Figure 24. At this higher energy, deviations from the expected rocking curve width ( 5 arc secs $x 0.45$ or 2.25 arc seconds) are observed. Because of the low grazing angle the beam makes with the surface $\left(2.5^{\circ}\right)$, the beam illuminates a much larger portion of the crystal (by a factor of about 7) than at $5 \mathrm{keV}$, and therefore some of the broadening observed in the rocking curve may be attributed to a bowing of the entire crystal due to mounting. At $15 \mathrm{keV}$ with this asymmetry, the resulting surface power loading on the crystal is only 1.1 watts $/ \mathrm{mm}^{2}$ at $100 \mathrm{~mA}$. The $10 \%$ loss point in this case was found to be about $61 \mathrm{~mA}$ or about 0.7 watts $/ \mathrm{mm}^{2}$. This low value of the power loading at which a $10 \%$ loss of expected intensity was observed can be attributed to the poorer cooling performance of the core-drilled crystal in combination with the reduced acceptance of the second crystal due to the asymmetric geometry as compared to the symmetrically cut, slotted crystal. On the other hand, this asymmetrically cut crystal should increase the measured flux by about a factor of two over the symmetrically cut crystal because of the increase in acceptance of the first crystal. Experimentally we observed an increase in the flux from the asymmetrically cut crystal at $15 \mathrm{keV}$ of between 1.36 to 1.5 over that from the symmetrically cut crystal (as compared to the expected value of 2.2). Therefore the flux from the asymmetrically cut crystal at $61 \mathrm{~mA}$ (the $10 \%$ loss point) was equivalent to the intensity of the slotted, symmetric crystal at approximately $80-90 \mathrm{~mA}$. 


\section{Jet-Cooled Diamond Tests}

One day of beam time was devoted to the jet-cooled diamond tests. The diamond, measuring $6 \mathrm{~mm} \times 6$

$\mathrm{mm} \times 0.3 \mathrm{~mm}$, was fabricated synthetically (high temperature and pressure presses) by Sumitomo (Sumicrystal ${ }^{\circledR}$ ) and oriented with the (100) planes parallel to the large face. The diamond was attached to the holder with RTV silicone, a material we knew from past experiences to maintain its resiliency and strength even when subjected to high radiation doses. A schematic of the diamond and the jet-cooling apparatus is shown in Figure 25. Since this was our first experience with both diamonds and jet cooling, we proceeded carefully by aperturing the incident beam to a $1 \mathrm{~mm} \times 0.7 \mathrm{~mm}$ area giving an estimated total power of 17.5 watts (at $100 \mathrm{~mA}$ ) incident onto the crystal. A Si (531)-oriented crystal was used as the second crystal of the double-crystal monochromator providing a nearly dispersion-free setup [ $d=0.8918 \AA$ for diamond $(400)$ and $d=0.9178 \AA$ for $\mathrm{Si}(531)]$. The dispersion due to the wavelength spread can be written:

$$
\begin{aligned}
\Delta \Theta & =(\Delta \lambda / \lambda)\left(\tan \Theta_{1}-\tan \Theta_{2}\right) \\
& =(\Delta \lambda / \lambda) \tan \Theta_{1}\left(1-\tan \Theta_{2} / \tan \Theta_{1}\right) \\
& =\psi\left(1-\tan \Theta_{2} / \tan \Theta_{1}\right),
\end{aligned}
$$

where $\psi$ is the incident beam divergence. For the $15 \mathrm{keV}$ data with $\psi$ equal to 8.6 arc seconds (FWHM), the dispersion due to the mismatch in d-spacing between the two crystals is approximately 0.3 arc seconds. Figures 26 and 27 show the peak diffracted intensity and FWHM of the rocking curves as a function of storage ring current for water pressures of 15 and 25 psi, respectively. Data for both these figures were collected at $15 \mathrm{keV}$, because Bragg's law cannot be satisfied by $5 \mathrm{keV}$ photons using the diamond (400) planes. The good diffraction quality of the diamond is indicated by the narrow rocking curves obtained (less than 3 arc seconds). The peak intensity as a function of stored beam current shows a distinctly different curvature in the diamond data than it did in the silicon runs (see Figures 26 and 27). Rather than the slope decreasing as the current increases, the data show the slope of the curve increasing (and a corresponding decrease in rocking curve width, at least in the $15 \mathrm{psi}$ case). The source of this apparent increase in diffracted photons per unit beam current has yet to be unambiguously determined. One suggestion was that the RTV was slightly straining the crystal with no heat load, but, when the crystal was subjected to a heat load, the diamond mount heated up (due to the beam transmitted 
through the diamond and striking the mount) making the RTV more pliable and reducing the forces it was exerting on the crystal. Another suggestion was that as the diamond crystal heated up, the diamond (400) d-spacing better matched the $\mathrm{Si}$ (531) reflection and resulted in a more dispersion-free situation. However, that is doubtful because extremely high temperatures would have to be reached to make even a small change in the difference in the d-spacings between diamond and silicon and such a large temperature rise was not supported by the IR camera measurements, which indicated very little rise in surface temperature. Buoyed with this encouraging information, we decided to open the vertical slits to $2 \mathrm{~mm}$ and the horizontal slits to $3 \mathrm{~mm}$ (estimated power of approximately 100 watts incident on the crystal at $100 \mathrm{~mA}$ ). Alignment was done at $4 \mathrm{~mA}$ and the rocking curve from the alignment process (with 15 psi water flow) is shown in Figure 28. Note that the curve is considerably broader than the previous runs with the smaller beam size. The origin of the broadening is thought to be due to the larger beam size sampling a larger area of the slightly mosaic diamond. When the storage ring was filled to $100 \mathrm{~mA}$, the RTV softened and the diamond gave way under the pressure of the water jet. We do not believe that the softening of the RTV was due to heat that was deposited in the diamond but rather was due to the undulator beam passing through the diamond and striking the copper wall of the diamond mount, which was not well cooled. Because this was the final day of the run, the diamond work was not pursued further.

\section{Summary of the Results}

As stated in the Introduction, the primary purpose of the gallium-cooled silicon experiments was to reevaluate our previously measured value of the surface power loading at which there is appreciable degradation of the diffraction performance. In this study, we have defined "appreciable degradation" when we observe a $10 \%$ loss of flux from that expected. (The expected value is extrapolated from flux measurements at low current values.) For a given surface power loading, this degradation point is a function of both the crystal reflection used and $\mathrm{x}$-ray energy because both influence the rocking curve width, which sets the angular scale for the distortions that can be tolerated. Hence, we have performed measurements at two energies, 5 and $15 \mathrm{keV}$, during this study. One of the primary concerns when analyzing these data, particularly the slotted crystal data, is the influence of residual strains from fabrication and mounting. At low energies, the effect is minimal, but at higher energies the strain broadening can be a significant fraction of the theoretical Darwin width. Clearly, one outcome of this study 
will be a rejuvenated pursuit of improved bonding techniques for silicon crystals. In parallel, work will also continue on a topography system which should provide us with better strain assessment capabilities.

Notwithstanding the residual strains, the data collected at $5 \mathrm{keV}$ from symmetrically cut $\mathrm{Si}$ (111) crystals has reconfirmed our previous estimates that gallium-cooled slotted crystals cannot operate efficiently when surface power loadings exceed the $4-5$ watts $/ \mathrm{mm}^{2}$ value with a gallium flow of at least $1.5 \mathrm{gpm}$. For $15-\mathrm{keV}$ operation, the value is reduced to approximately 2 watts $/ \mathrm{mm}^{2}$, as would be expected from the increased sensitivity to distortions due to the narrower Darwin widths. However, it should be pointed out that these are not the surface power densities at which no further flux is observed as the current is increased. In fact, even for the $15-\mathrm{keV}$ case, we were still obtaining over $70 \%$ of the expected flux at $100 \mathrm{~mA}$ operation, and therefore the results should be considered in light of this fact.

Figure 21 shows that the surface temperature rise can be reduced by going to higher gallium flow rates. Recall that most of the data presented here were collected with a gallium flow rate of $1.5 \mathrm{gpm}$ to minimize the coolant-pressure-induced distortions. Clearly some improvement can be expected by going to higher gallium flow rates; but how much improvement can be expected? Unfortunately, the answer is probably not much. One approach to estimating the amount of improvement that could be expected is to examine the Biot number for the system. The Biot number is defined as the ratio of thermal resistance of the material to that at the coolant/material interface $(\mathrm{ht} / \mathrm{K}$, where $\mathrm{h}$ is the heat transfer coefficient of the coolant, $\mathrm{t}$ the faceplate thickness, and $\mathrm{K}$ the thermal conductivity of the material being cooled). When this ratio is larger than 1 , then the maximum temperature rise in the component is largely controlled by the materials properties of the component $(\mathrm{t}$ and $\mathrm{\kappa}$ ) and not the coolant properties. This point can be illustrated using the epoxy-bonded crystal. With a faceplate thickness of $0.8 \mathrm{~mm}$, this crystal was fabricated with 32 slots each $0.8 \mathrm{~mm}$ wide and $2.7 \mathrm{~mm}$ deep (see Figure 3). The heat transfer coefficient as a function of flow rate for this crystal is shown in Figure 29. (The heat transfer coefficient was calculated using the correlation recommended by Baker and Tessier 6 for liquid metals.) Also plotted in Figure 29 is the Biot number as a function of flow rate, and one can see that, even at low flow rates, the Biot number is already greater than unity. Hence a substantial reduction in surface temperature is not to be expected for much higher flow rates. So although some improvement is to be expected by going to higher gallium flow rates, as our experiments have shown, thinner faceplates should also be seriously considered. The limit of the faceplate 
thickness will ultimately be determined by its ability to withstand deformation by the pressure of the coolant. To withstand the pressure distortions with thinner faceplates, narrower channels may be required so that the span of the faceplate is reduced. Future R\&D plans for gallium-cooled crystals will include improved bonding techniques to allow for increased gallium flow rates (up to the maximum capacity of the pump, which is about 4-5 gpm), thinner faceplates, and, if necessary, modified channel geometries to support the thinner faceplates.

The core-drilled coolant channels of the asymmetrically cut crystal did not perform as well from a heat transfer point of view as did the slots. The crosssection of the slots in the bonded crystals $\left(2.16 \mathrm{~mm}^{2}\right)$ was comparable to the core-drilled holes $\left(2.01 \mathrm{~mm}^{2}\right)$, but there were about half as many holes as slots (17 versus 32 ). This means that, for a given coolant flow rate, the core-drilled crystal should have a higher fluid velocity and hence heat transfer coefficient. However, the thicker faceplate of the core-drilled crystal (1.48 $\mathrm{mm}$ as compared to $0.8-1.0 \mathrm{~mm}$ for the slotted crystals) coupled with the wider spacing of the core-drilled holes with the rounded tops seems to have resulted in a reduced thermal performance over the'slotted crystals. We have already fabricated a new core-drilled crystal with a faceplate of $0.8 \mathrm{~mm}$ and await another opportunity to test this new configuration.

Few quantitative results can be gleaned from our abbreviated diamond run. However, the performance of the diamond subjected to small beams has given us encouragement, and we will continue to pursue this avenue of research more actively in the upcoming year.

\section{References}

1. Bilderback, D.H., et al., Rev. Sci. Instrum. 60, 1419, 1989.

2. Mills, D.M., et al., Nucl. Instr. and Meths A291, 481, 1990.

3. Frit bonding performed by Rocketdyne Albuquerque, $2511 \mathrm{C}$ Broadbent Parkway NE, Albuquerque, NM 87107

4. The die-attach paste used in this experiment was Johnson Matthey JM 4613 AuSub ${ }^{\circledR}$ Die Attach Paste.

5. The epoxy used in this experiment was 3M Scotch-Weld ${ }^{\mathrm{TM}} 1838 \mathrm{~B} / \mathrm{A}$ Green Epoxy Adhesive.

6. Handbook of Electromagnetic Pump Technology, Chapter III, R.S. Baker and M.J. Tessier, Elsevier Science Publishing Co., New York, NY, 1987. 


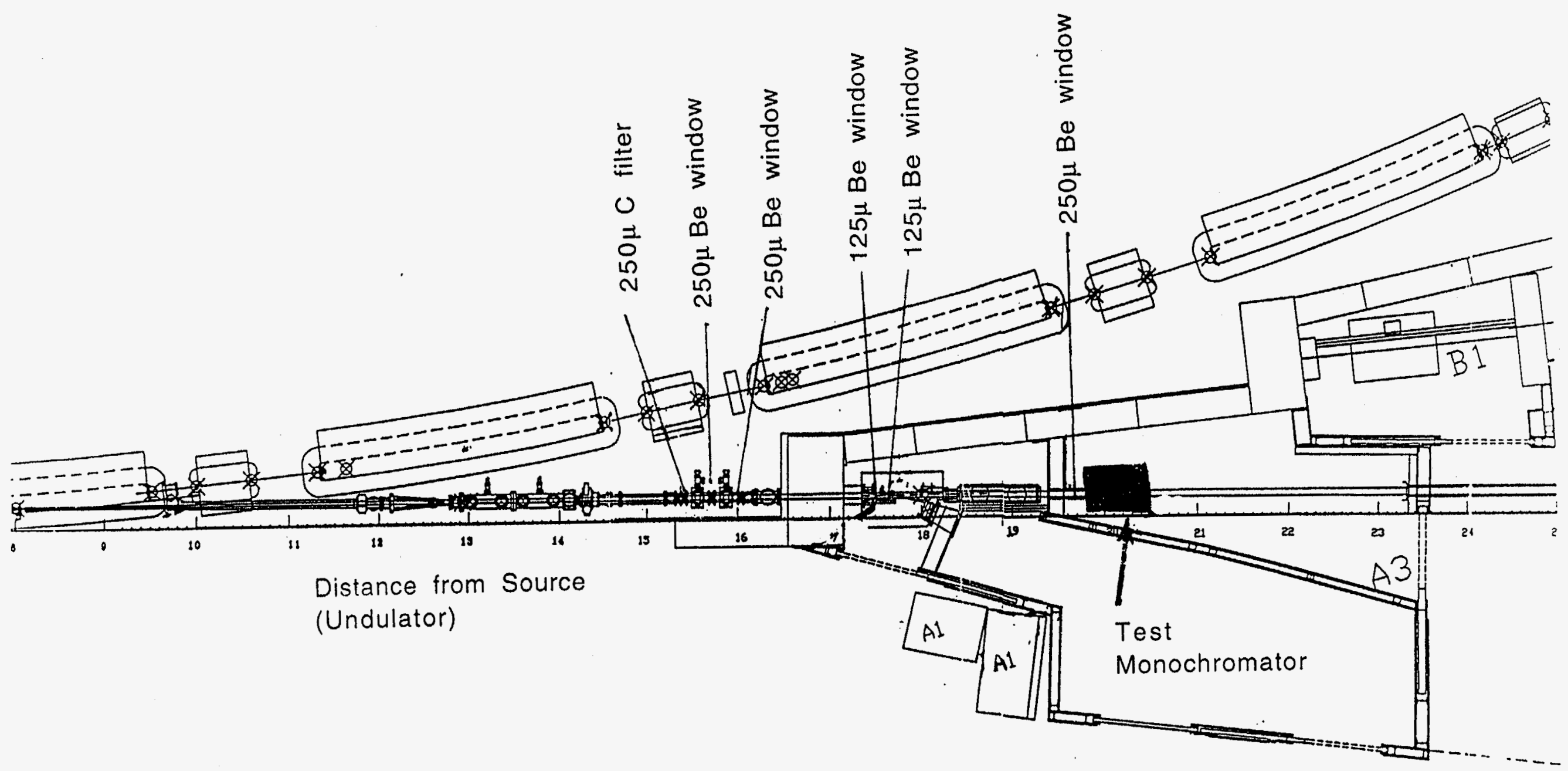

Figure 1. Beamline layout for the CHESS A-line where the experiments were carried out. The monochromator test location in the A-3 station was 20 meters from the undulator. A total of 250 microns of carbon and 1000 microns of beryllium were between the undulator and the monochromator. 


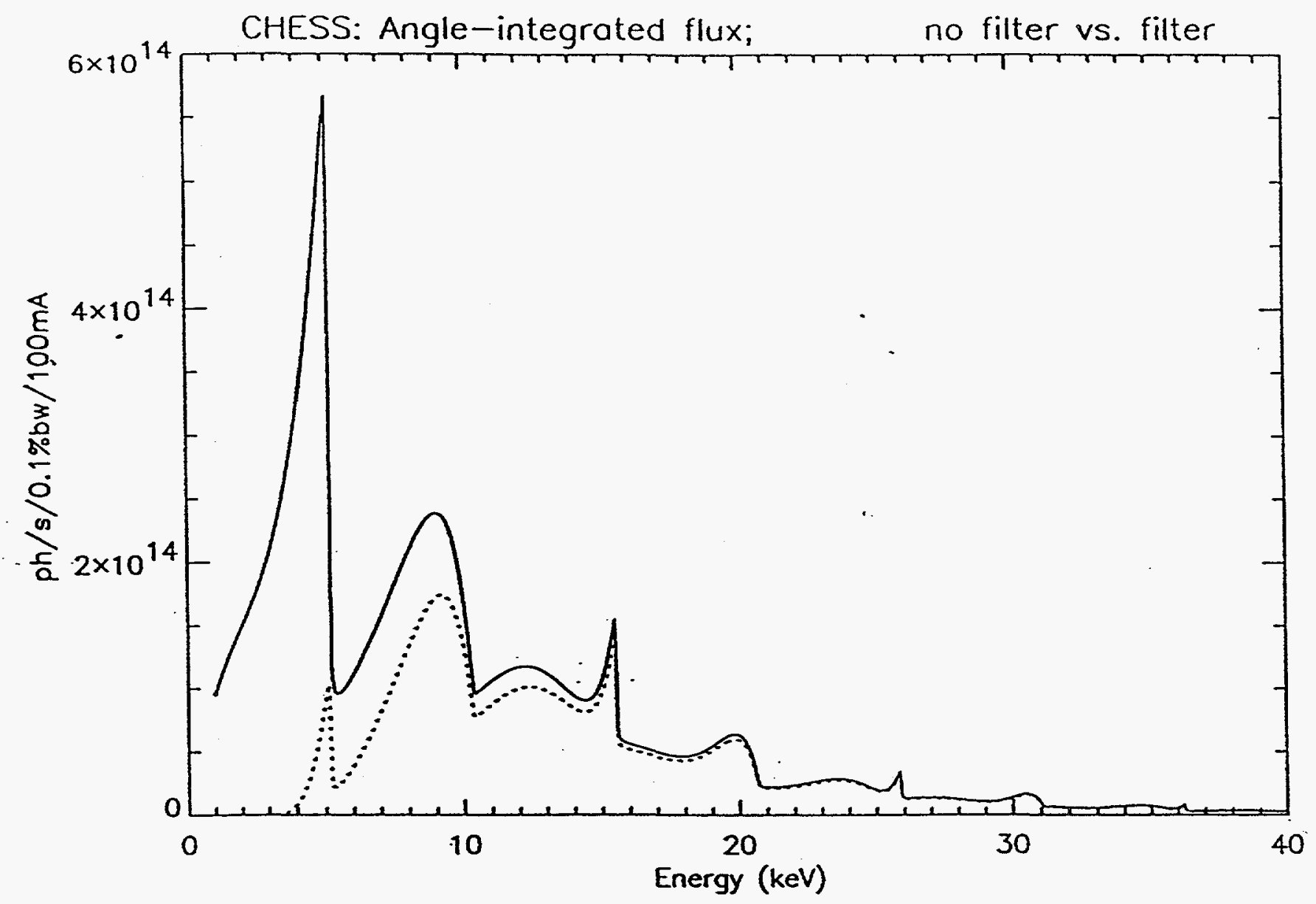

Figure 2. The raw undulator spectrum (solid line) and the spectrum after the carbon filter and beryllium windows (dotted line) as a function of energy. The parameters for the spectral calculations are as follows: 5.43 $\mathrm{GeV}, 100 \mathrm{~mA}, \mathrm{~K}=1.14$. 

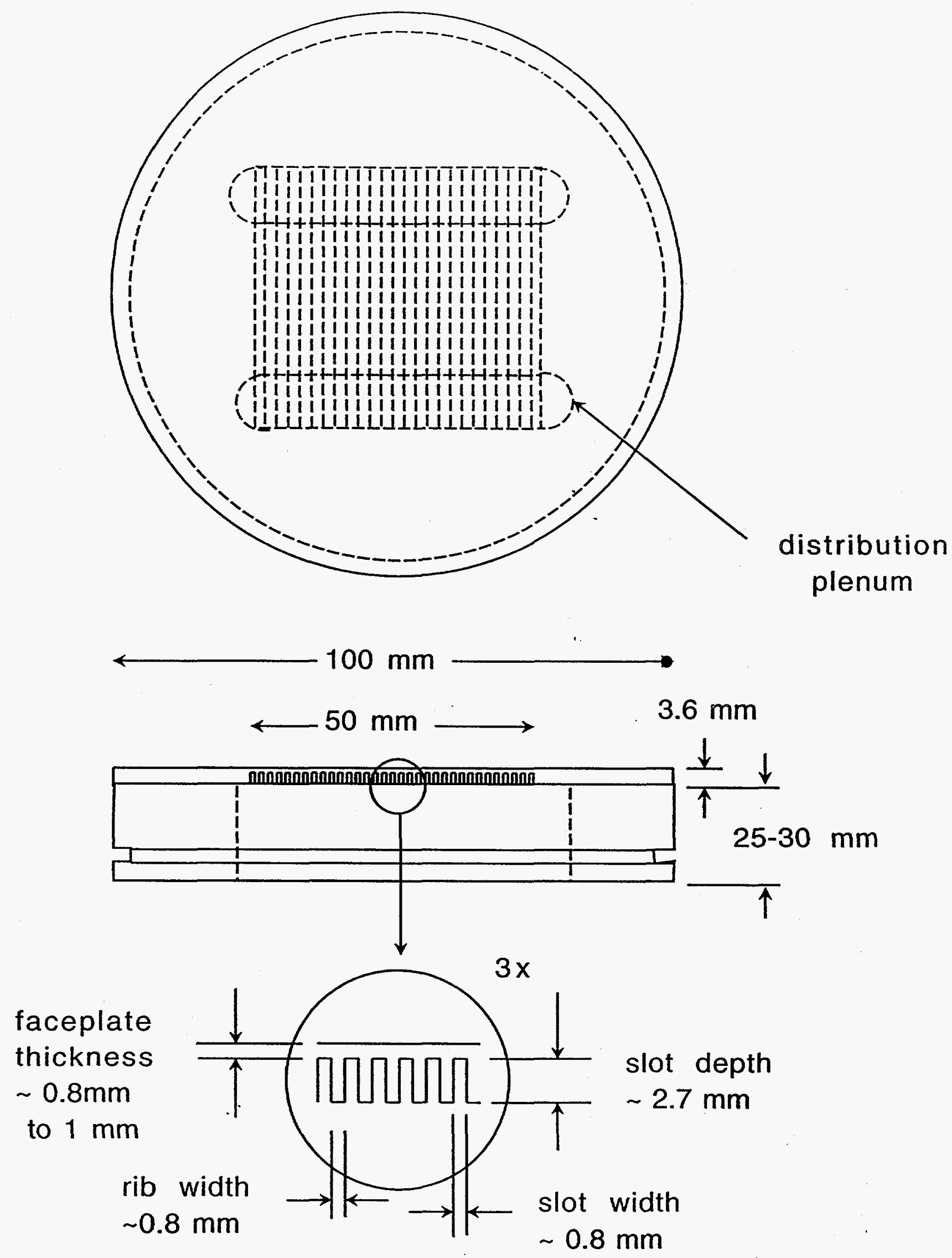

Figure 3. Schematic of the slotted crystal geometry showing slot width $(0.8 \mathrm{~mm})$ and depth $(2.7 \mathrm{~mm})$. The faceplate thicknesses for the die-attach- and epoxy-bonded crystals were 1.0 and $0.8 \mathrm{~mm}$, respectively. The cooled area was approximately $50 \mathrm{~mm} \times 50 \mathrm{~mm}$. 


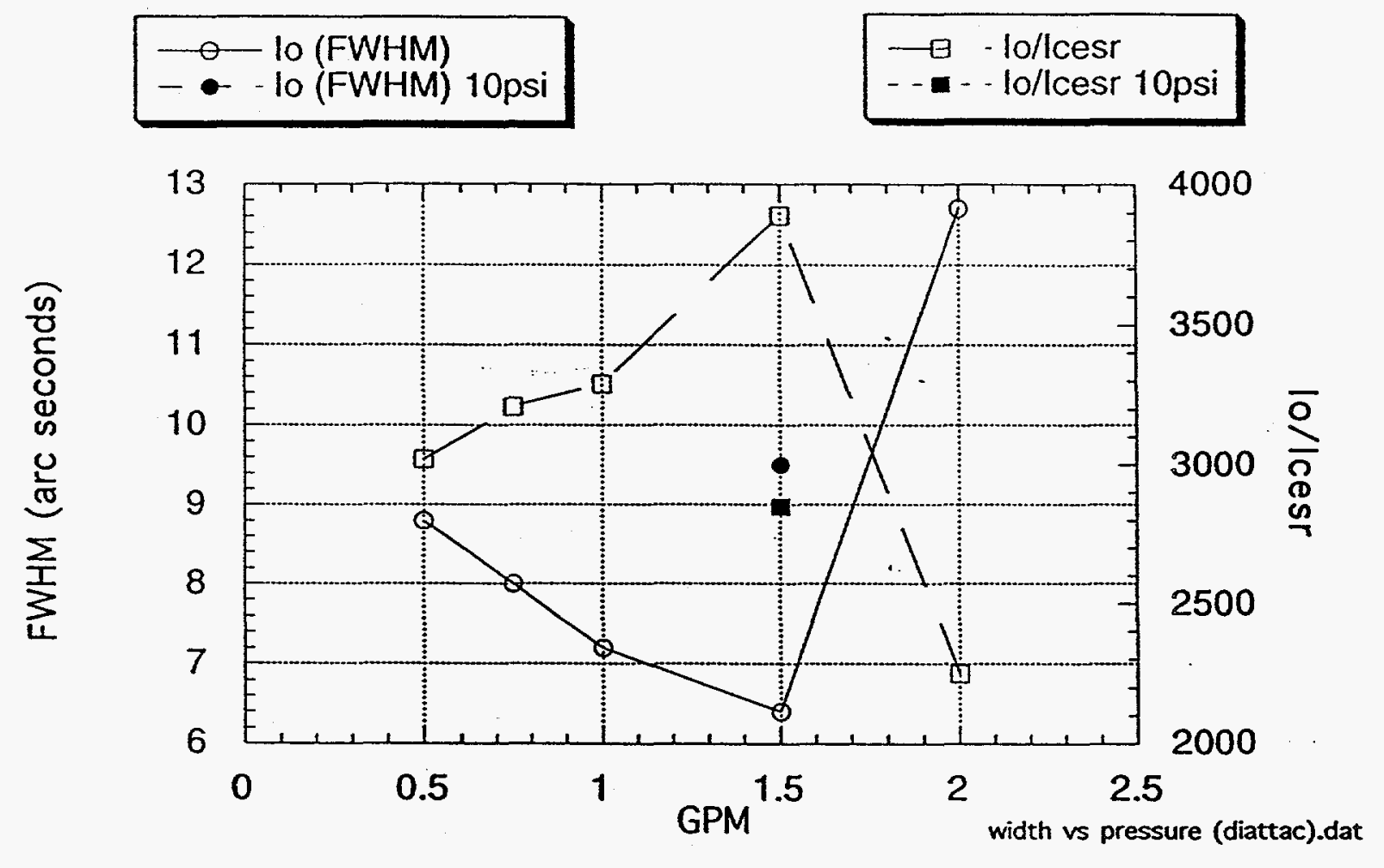

Figure 4. Plot of the FWHM of the rocking curve and measured intensity (Io) normalized to the storage ring current (Icesr) as a function of gallium flow rate for the die-attach-bonded crystal. Data was collected at $15 \mathrm{keV}$. Open data points show the data collected with a vacuum drawn on the coolant loop, and solid data points represent a 10 psi pressure applied to the coolant loop. The reduction of normalized intensity (or correspondingly the increased FWHM of the rocking curve) when the loop is pressurized is an indication that the bonding of the fins to the substrate may be degrading. 


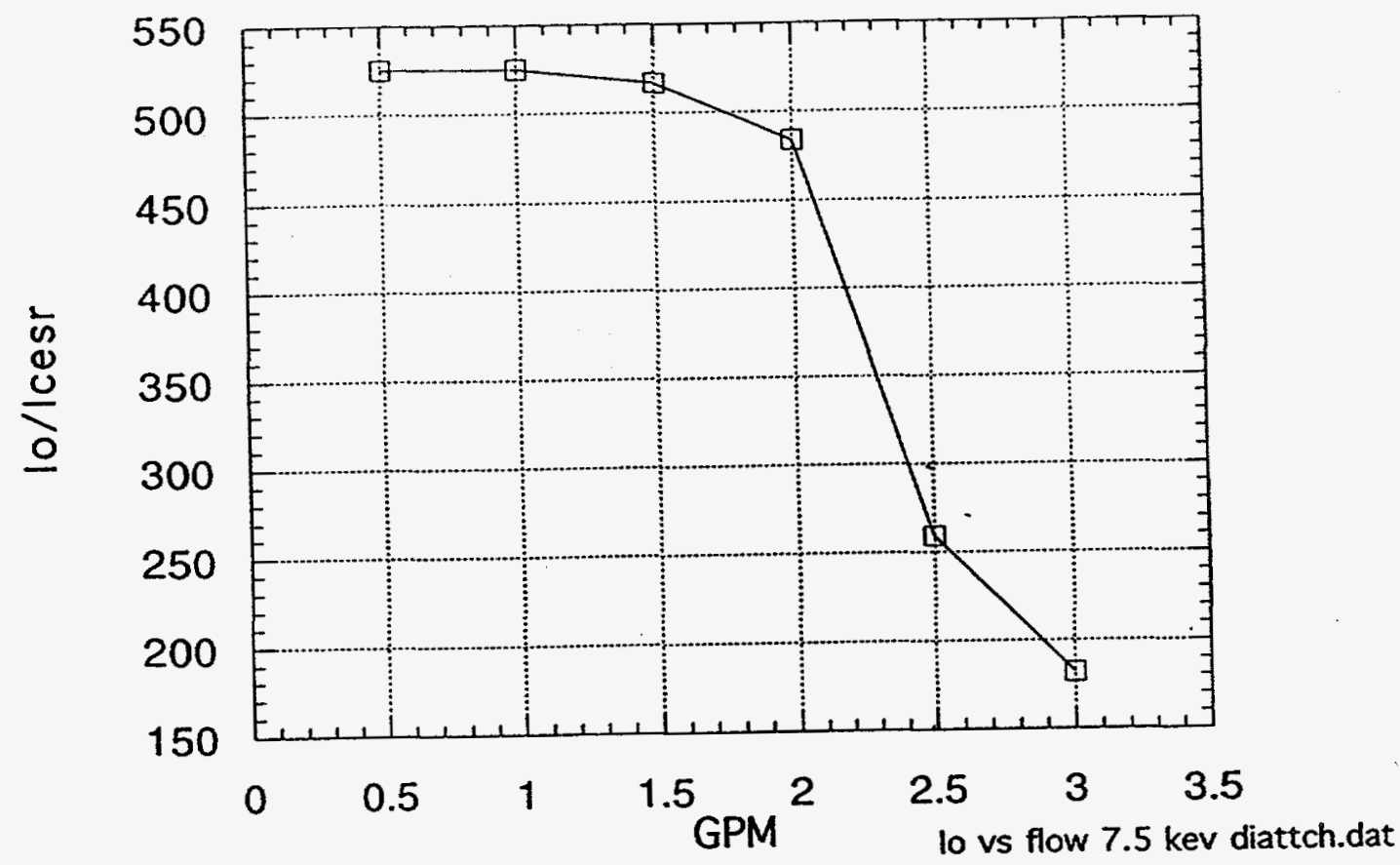

Figure 5. Plot of the normalized intensity (Io/Icesr) as a function of flow rate for the die-attach-bonded crystal taken at $7.5 \mathrm{keV}$. The reduction of intensity as the flow rate is increased is an indication of coolantpressure-induced distortions of the crystal. 


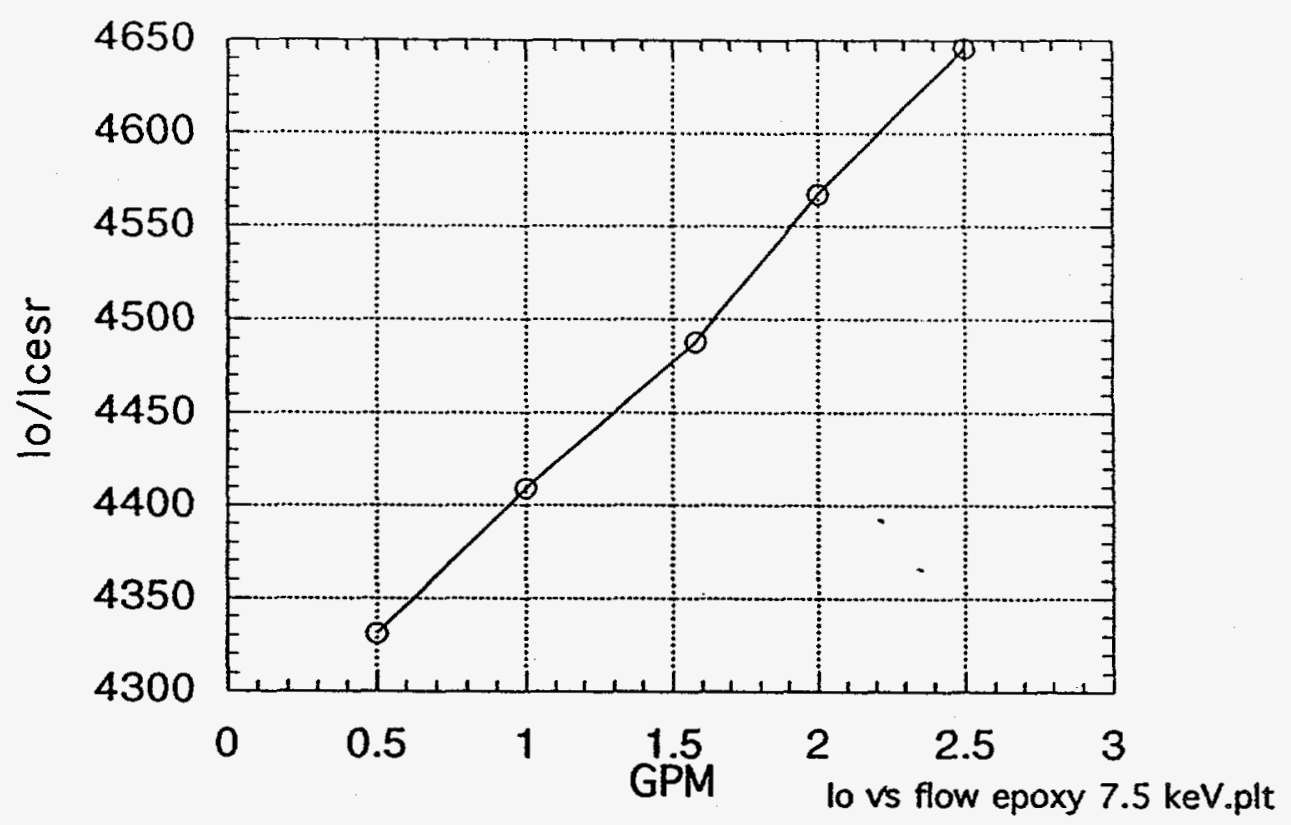

Figure 6. Plot of the normalized intensity (Io/Icesr) as a function of flow rate for the epoxy-bonded crystal taken at $7.5 \mathrm{keV}$. The monotonic increase of intensity as the flow rate indicates that the coolant pressure is not distorting the crystal. 


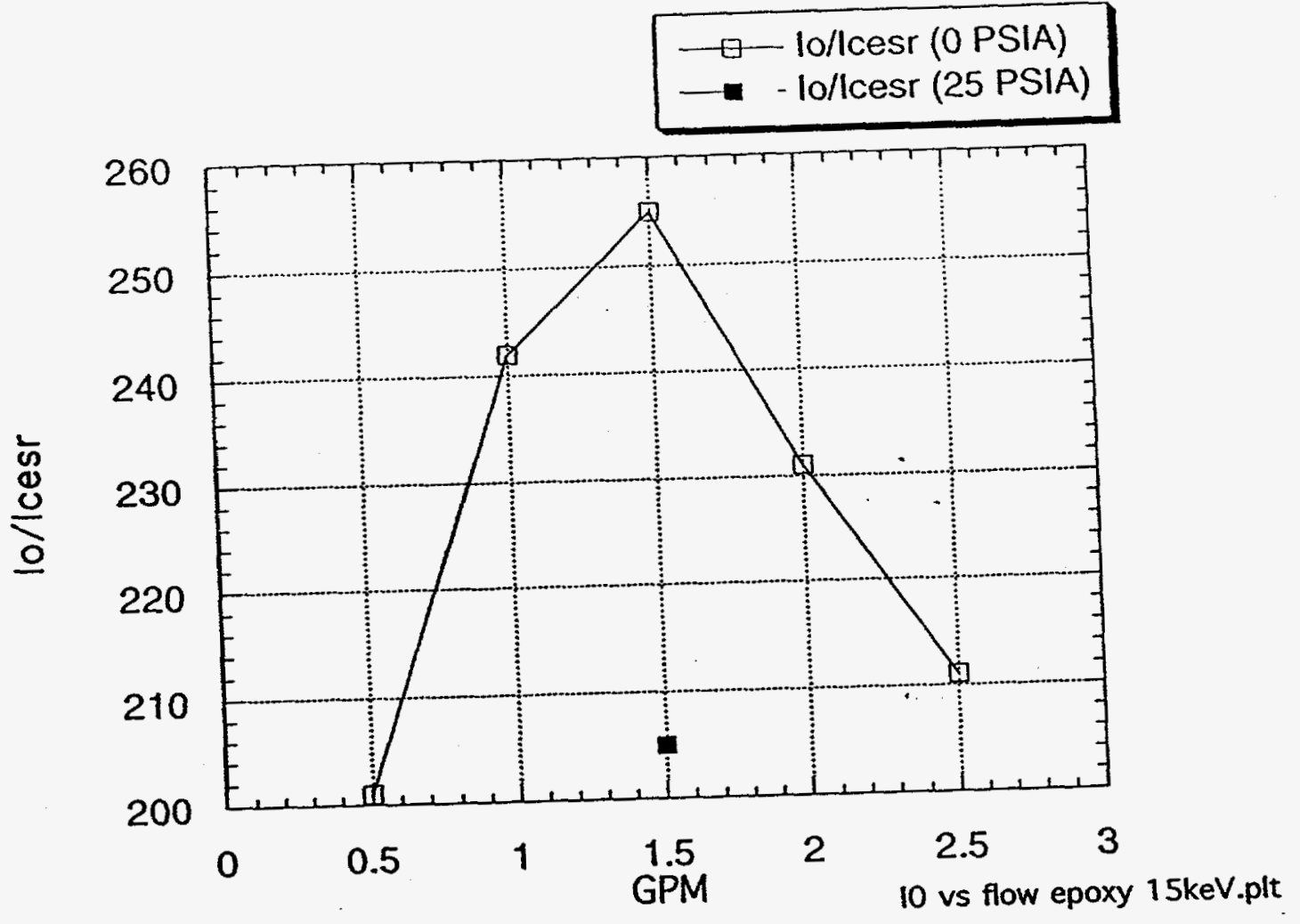

Figure 7. Plot of the normalized intensity (Io/lcesr) as a function of flow rate for the epoxy-bonded crystal taken at $15 \mathrm{keV}$. The reduction of intensity as the flow rate is increased beyond $1.5 \mathrm{gpm}$ is an indication of coolant-pressure-induced distortions of the crystal at higher flow rates. This is supported by the fact that, when the coolant loop is pressurized, the intensity is reduced (solid datum point). However the effect in the epoxy-bonded crystal is considerably less than in the die-attach-bonded crystal. 


\section{0}

8a)

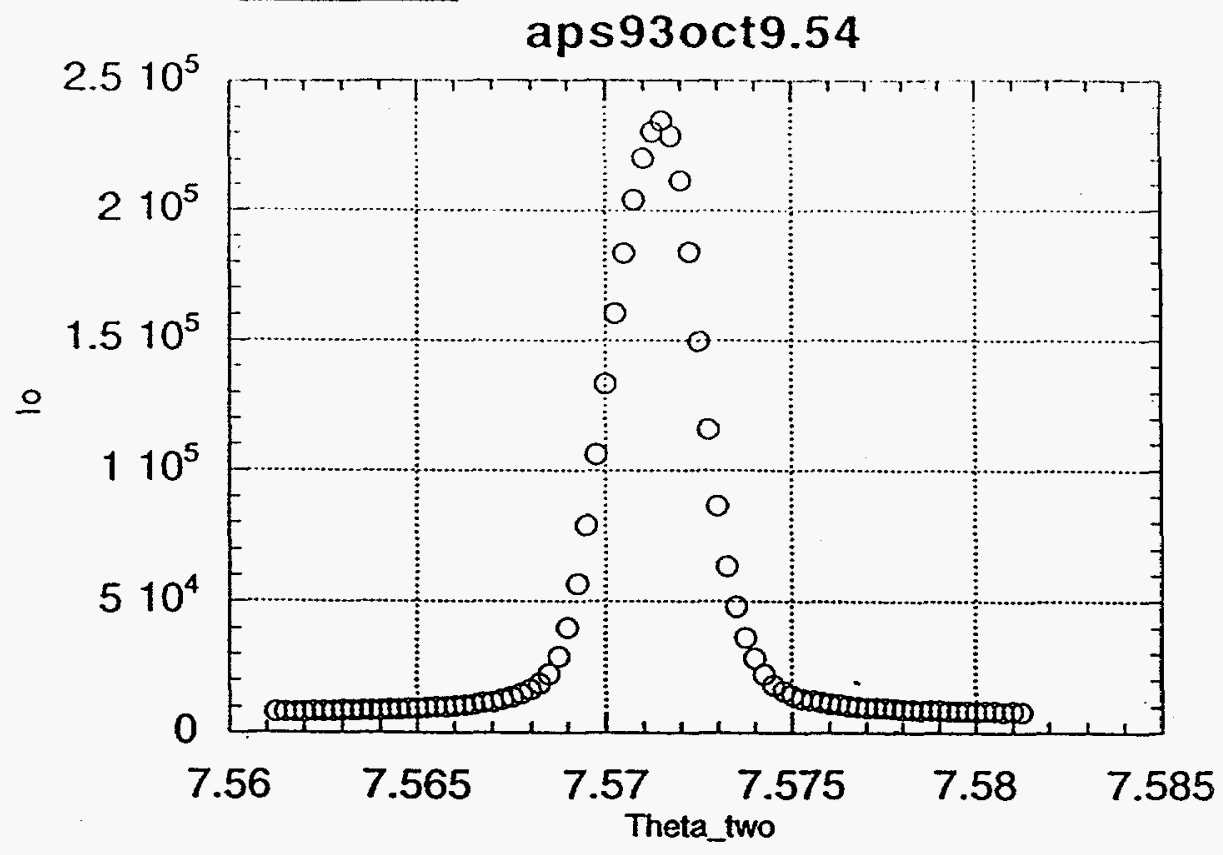

8b)

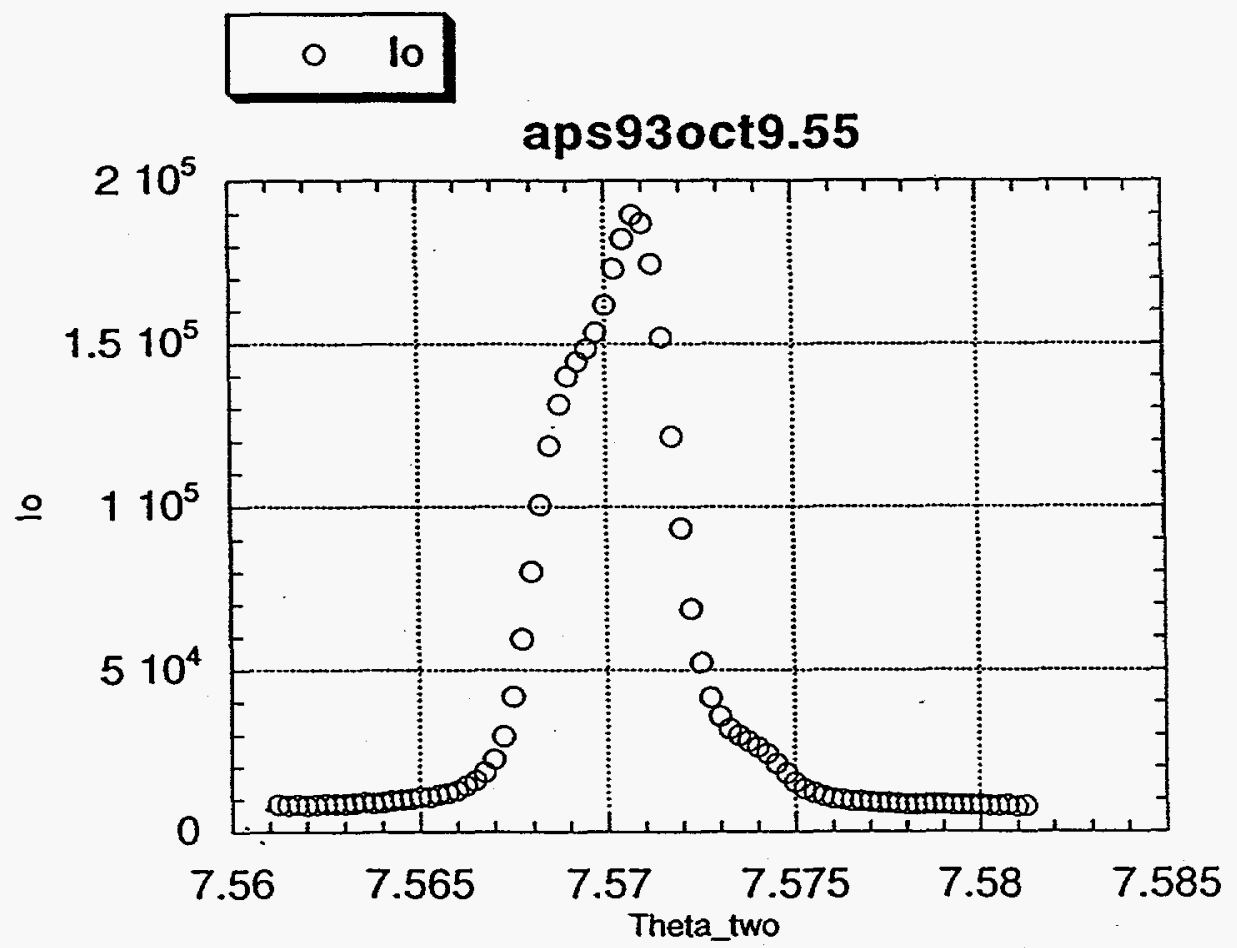

Figure 8 Rocking curves of the epoxy-bonded crystal taken at $15 \mathrm{keV}$ with (a) a vacuum drawn on the coolant loop and (b) with 25 psi of pressure applied to the coolant loop. 


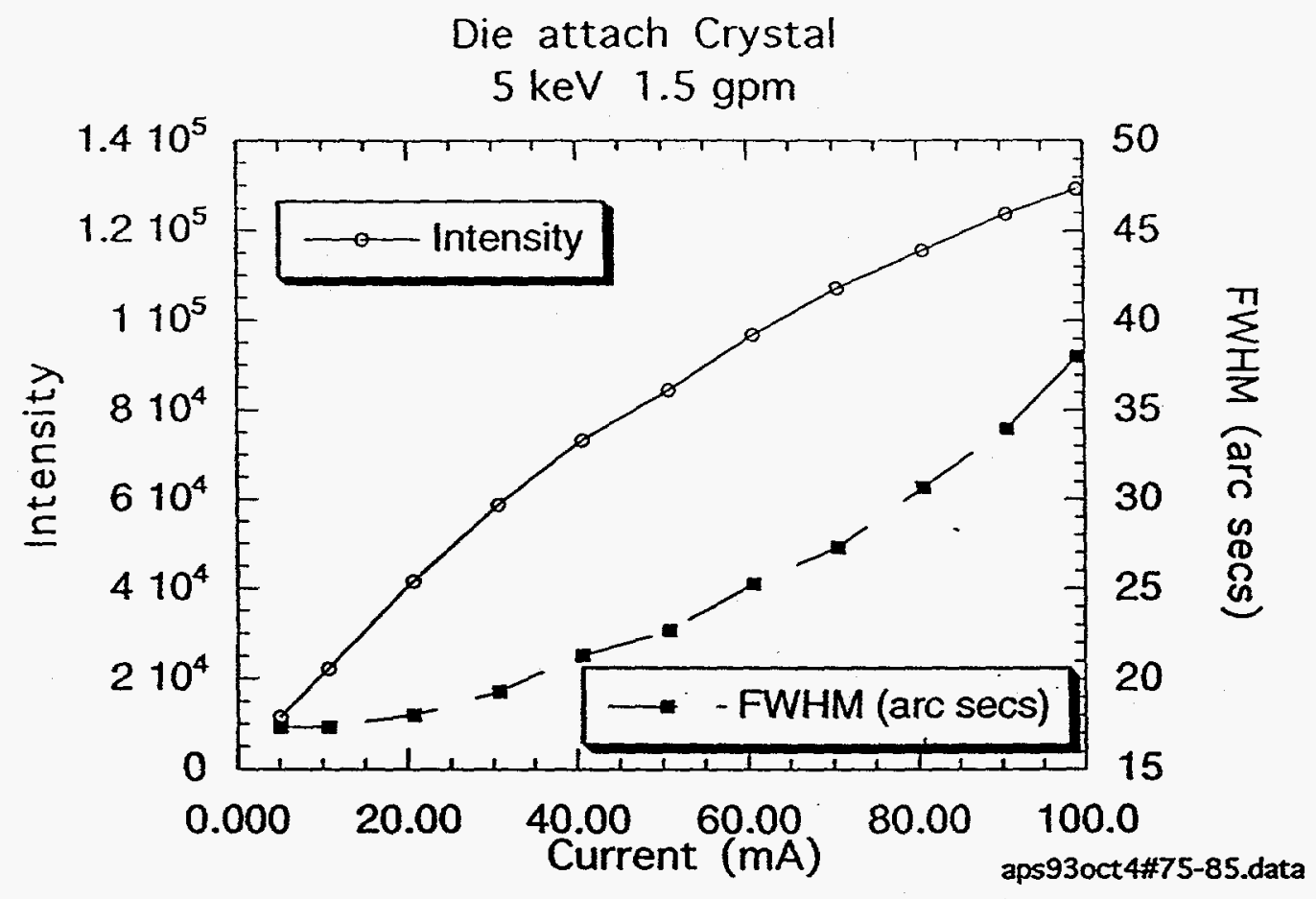

Figure 9. Plot of the intensity and FWHM of the Si (111) rocking curve as a function of stored beam current for the die-attach-bonded slotted crystal. (The normal incidence power density is about 25 watts $/ \mathrm{mm}^{2}$ at $100 \mathrm{~mA}$.) Data were collected at $5 \mathrm{keV}$ with a $1.5 \mathrm{gpm}$ gallium flow rate. 


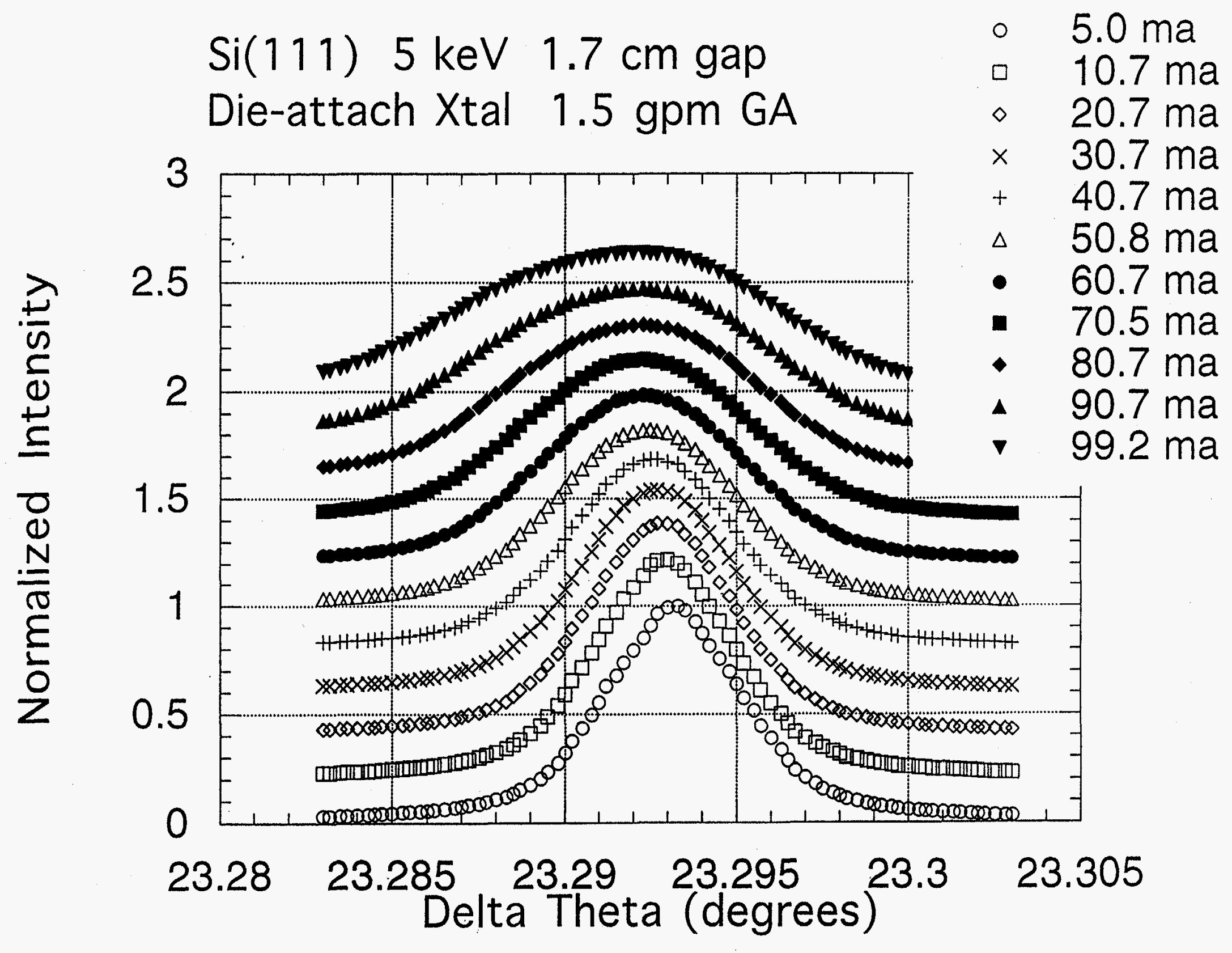
Figure 10. Normalized rocking curves for the data shown in Figure 9. All parameters identical to those in
Figure 9 . 


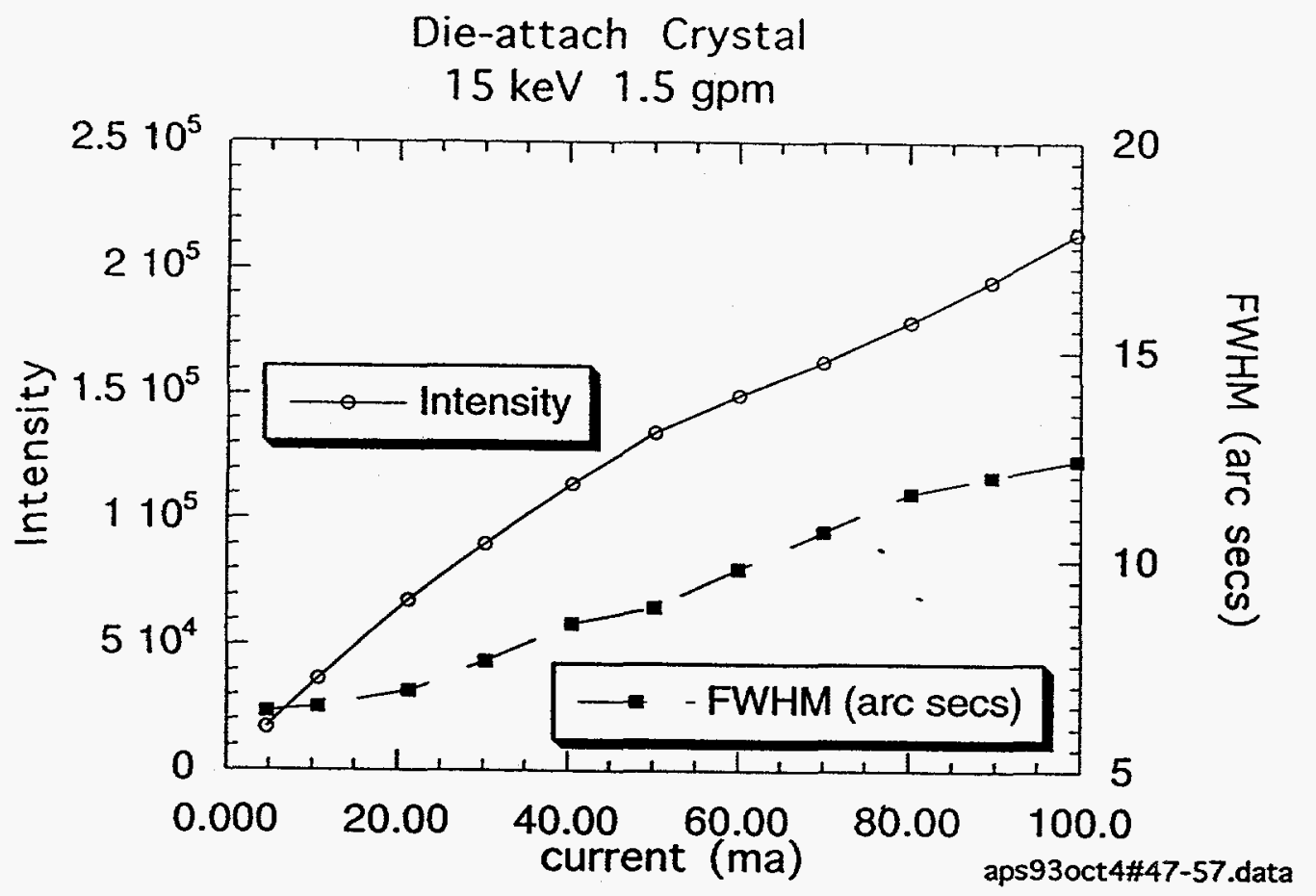

Figure 11. Plot of the intensity and FWHM of the Si (111) rocking curve as a function of stored beam current for the die-attach-bonded slotted crystal. (The normal incidence power density is about $25 \mathrm{watts} / \mathrm{mm}^{2}$ at $100 \mathrm{~mA}$.) Data were collected at $15 \mathrm{keV}$ with a $1.5 \mathrm{gpm}$ gallium flow rate. 


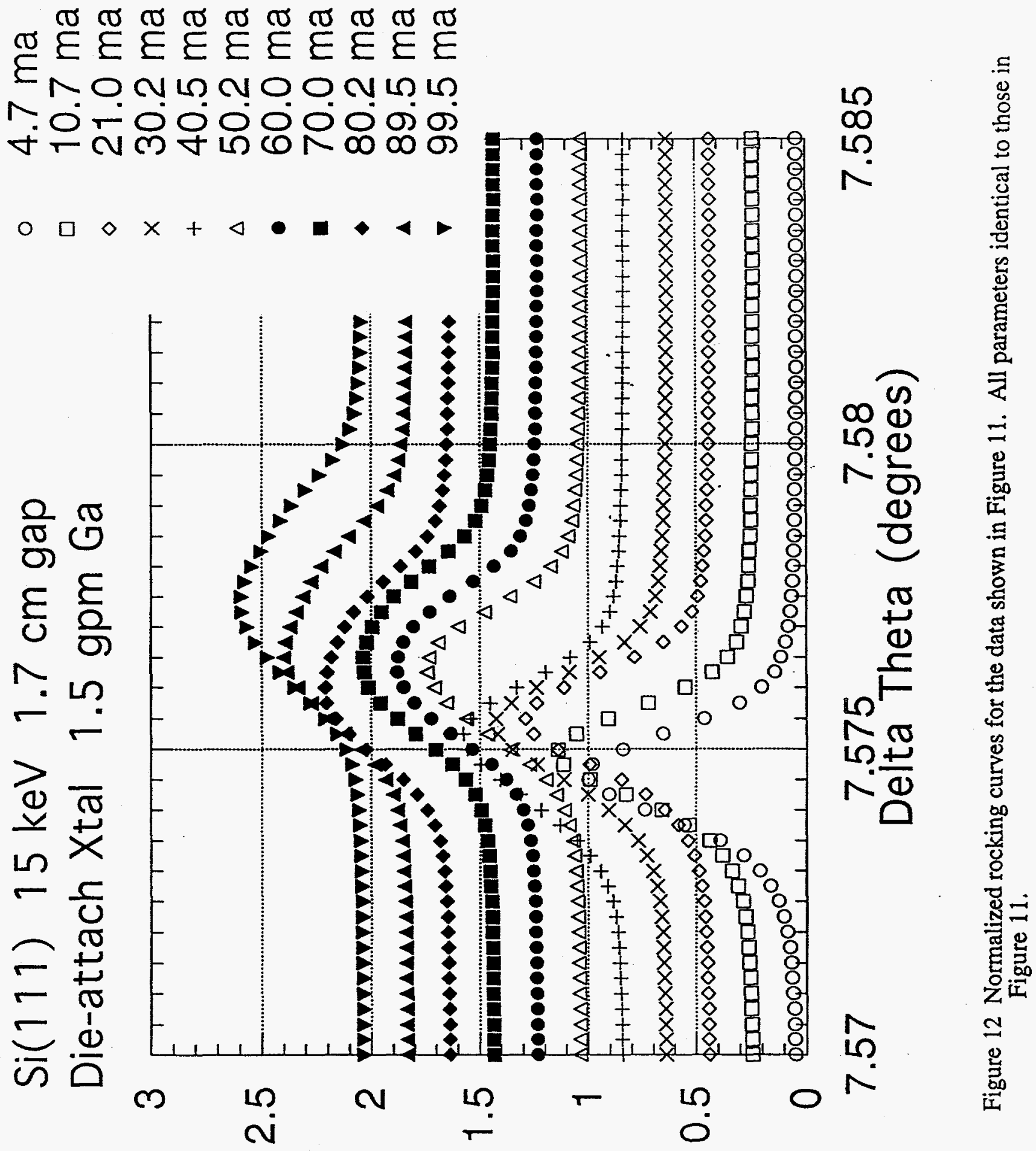

Kұ!suәzu| pəz!|emsoN 


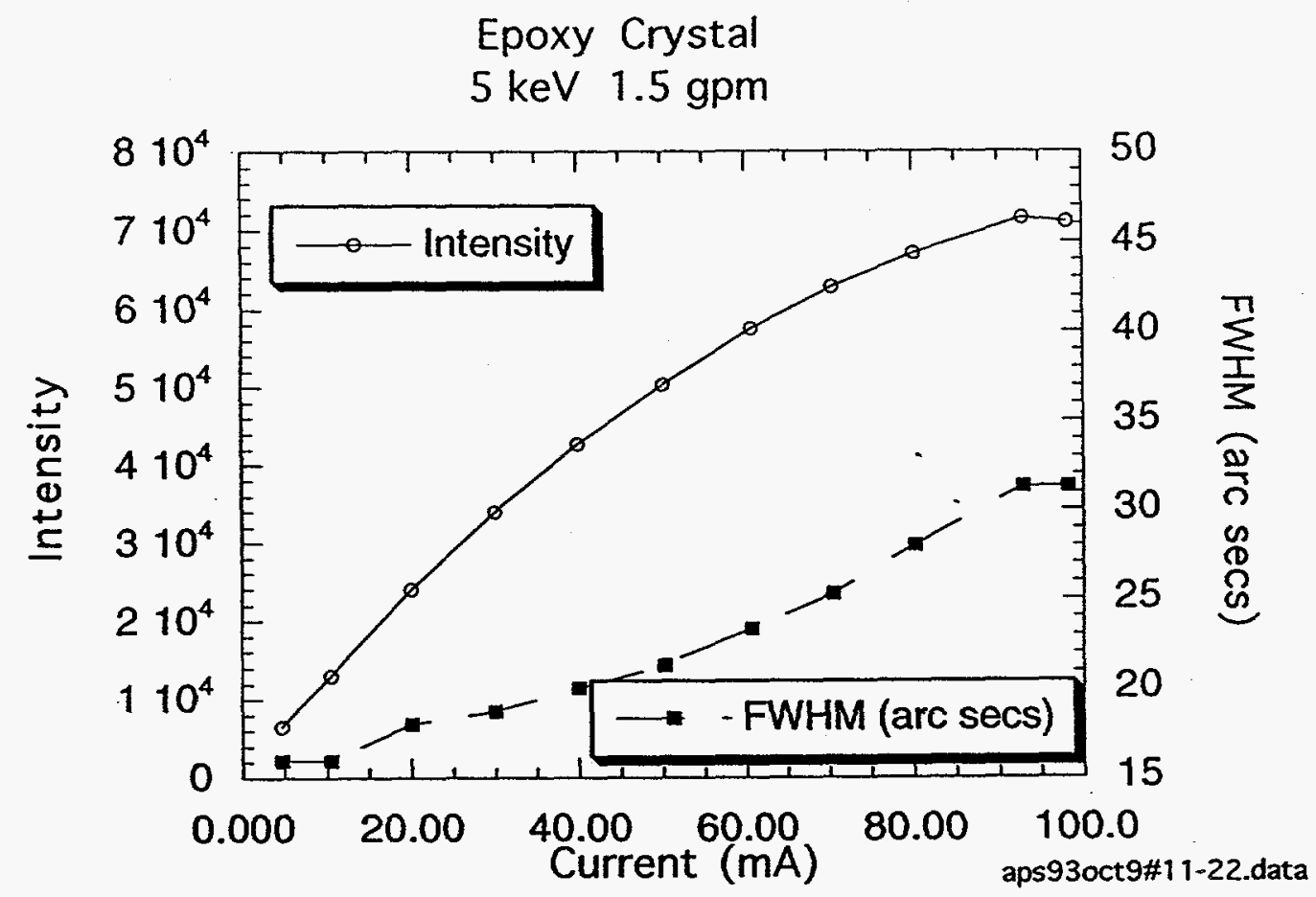

Figure 13. Plot of the intensity and FWHM of the Si (111) rocking curve as a function of stored beam current for the epoxy-bonded slotted crystal. (The normal incidence power density is about $25 \mathrm{watts} / \mathrm{mm}^{2}$ at $100 \mathrm{~mA}$.) Data were collected at $5 \mathrm{keV}$ with a $1.5 \mathrm{gpm}$ gallium flow rate. 


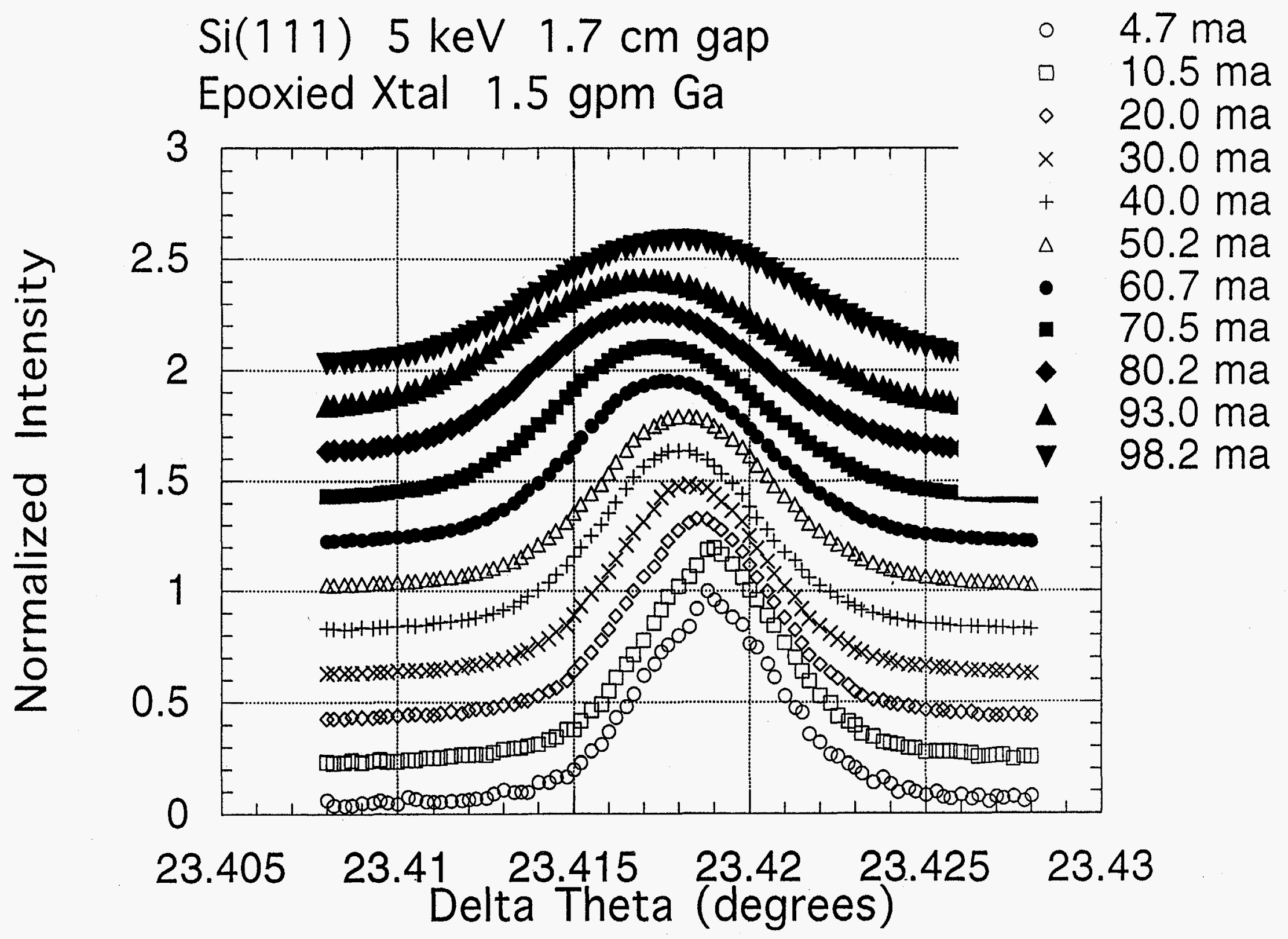

Figure 14. Normalized rocking curves for the data shown in Figure 13. All parameters identical to those in Figure 13. 


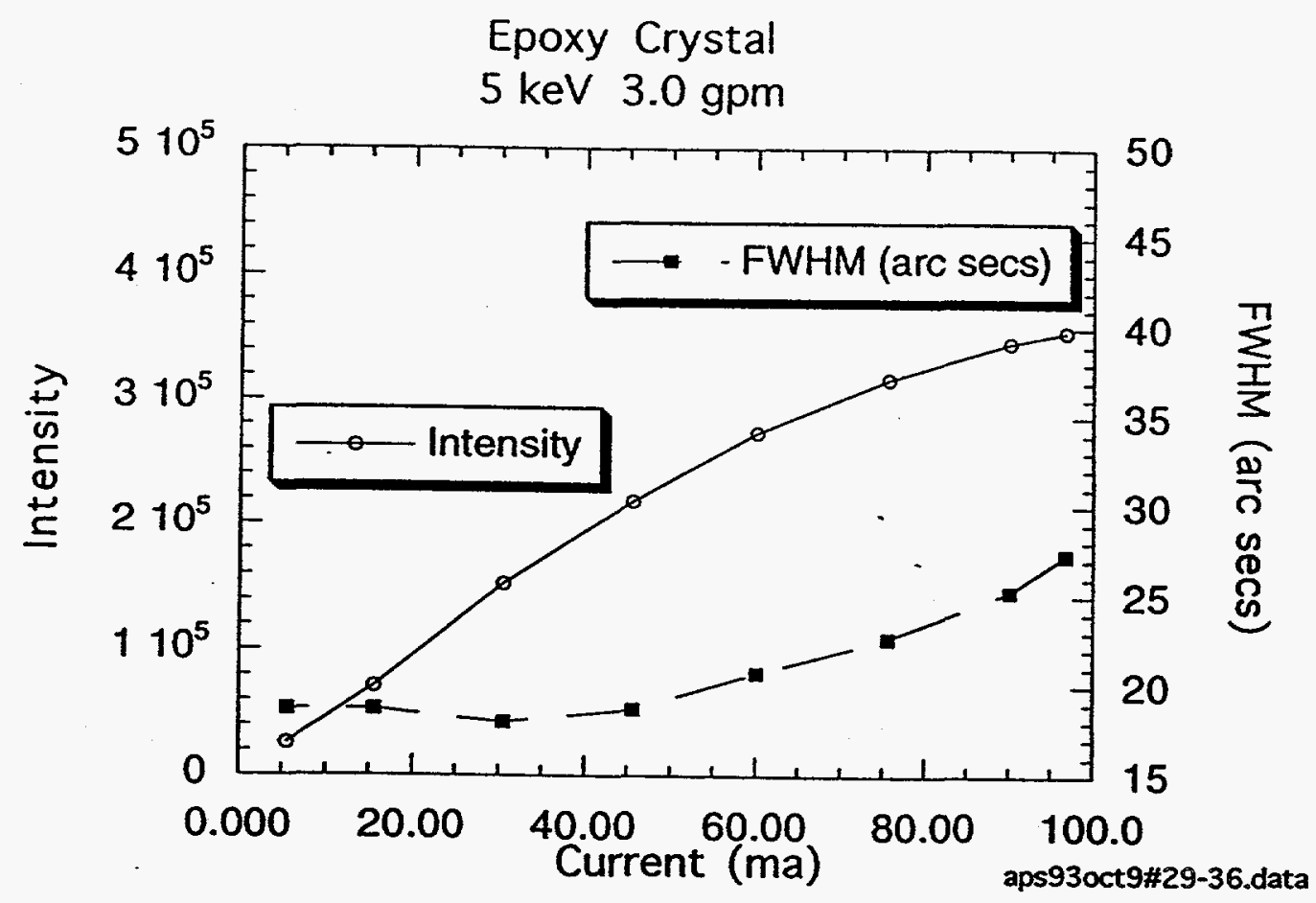

Figure 15. Plot of the intensity and FWHM of the Si (111) rocking curve as a function of stored beam current for the epoxy-bonded slotted crystal. (The normal incidence power density is about $25 \mathrm{watts} / \mathrm{mm}^{2}$ at $100 \mathrm{~mA}$.) Data were collected at $5 \mathrm{keV}$ with a $3.0 \mathrm{gpm}$ gallium flow rate. 


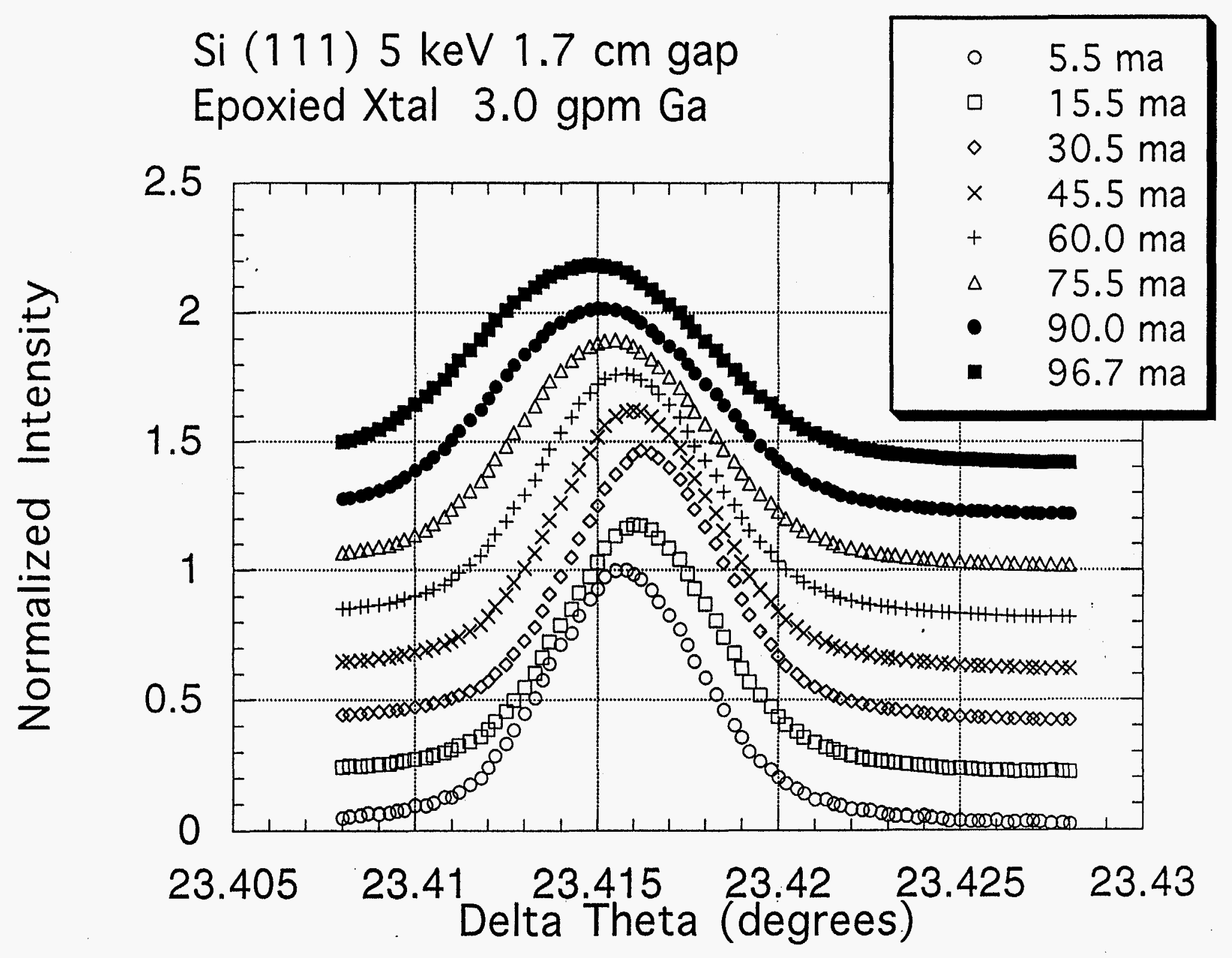

Figure 16. Normalized rocking curves for the data shown in Figure 15. All parameters identical to those in Figure 15. 


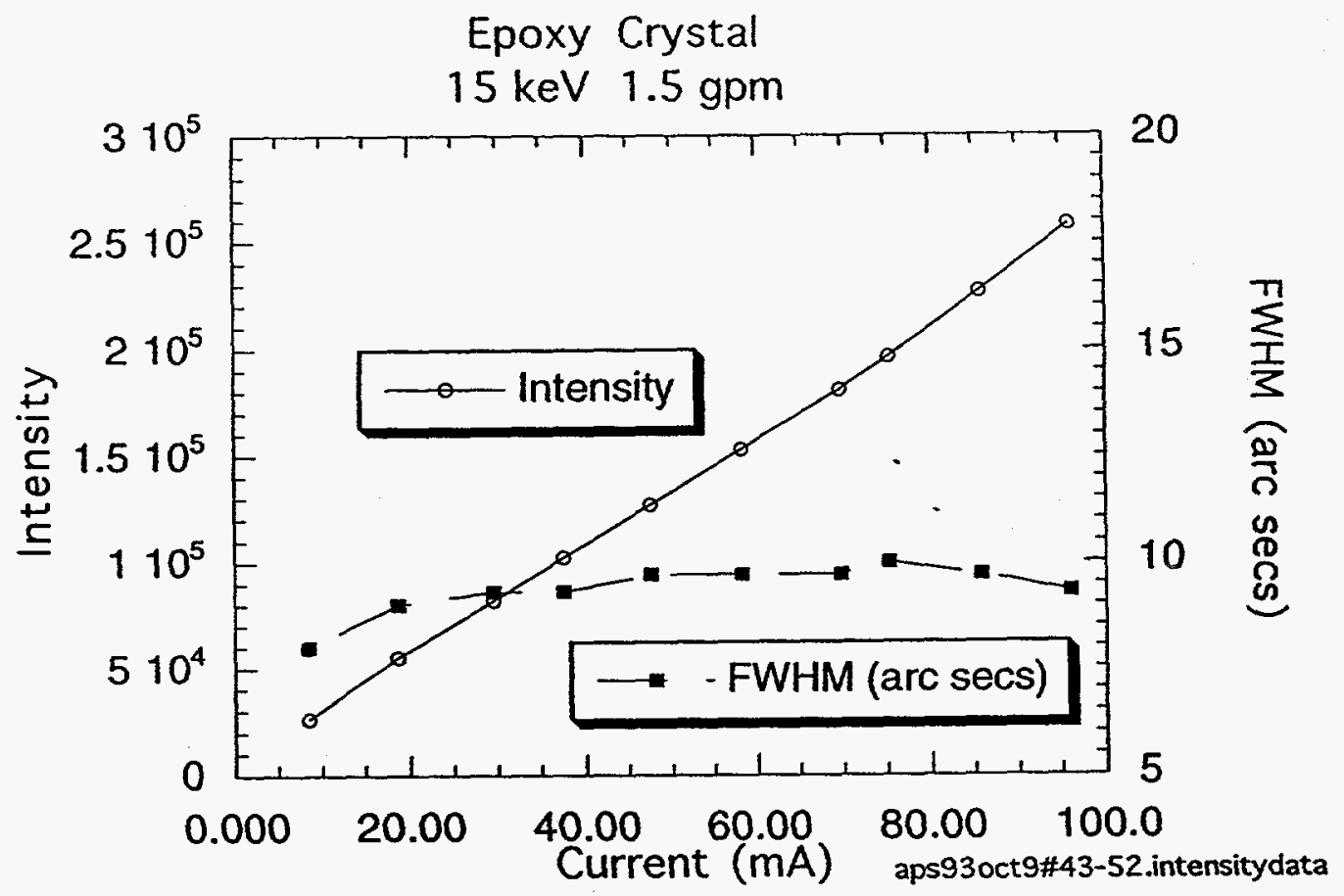

Figure 17. Plot of the intensity and FWHM of the Si (111) rocking curve as a function of stored beam current for the epoxy-bonded slotted crystal. (The normal incidence power density is about $25 \mathrm{watts} / \mathrm{mm}^{2}$ at $100 \mathrm{~mA}$.) Data were collected at $15 \mathrm{keV}$ with a $1.5 \mathrm{gpm}$ gallium flow rate. 


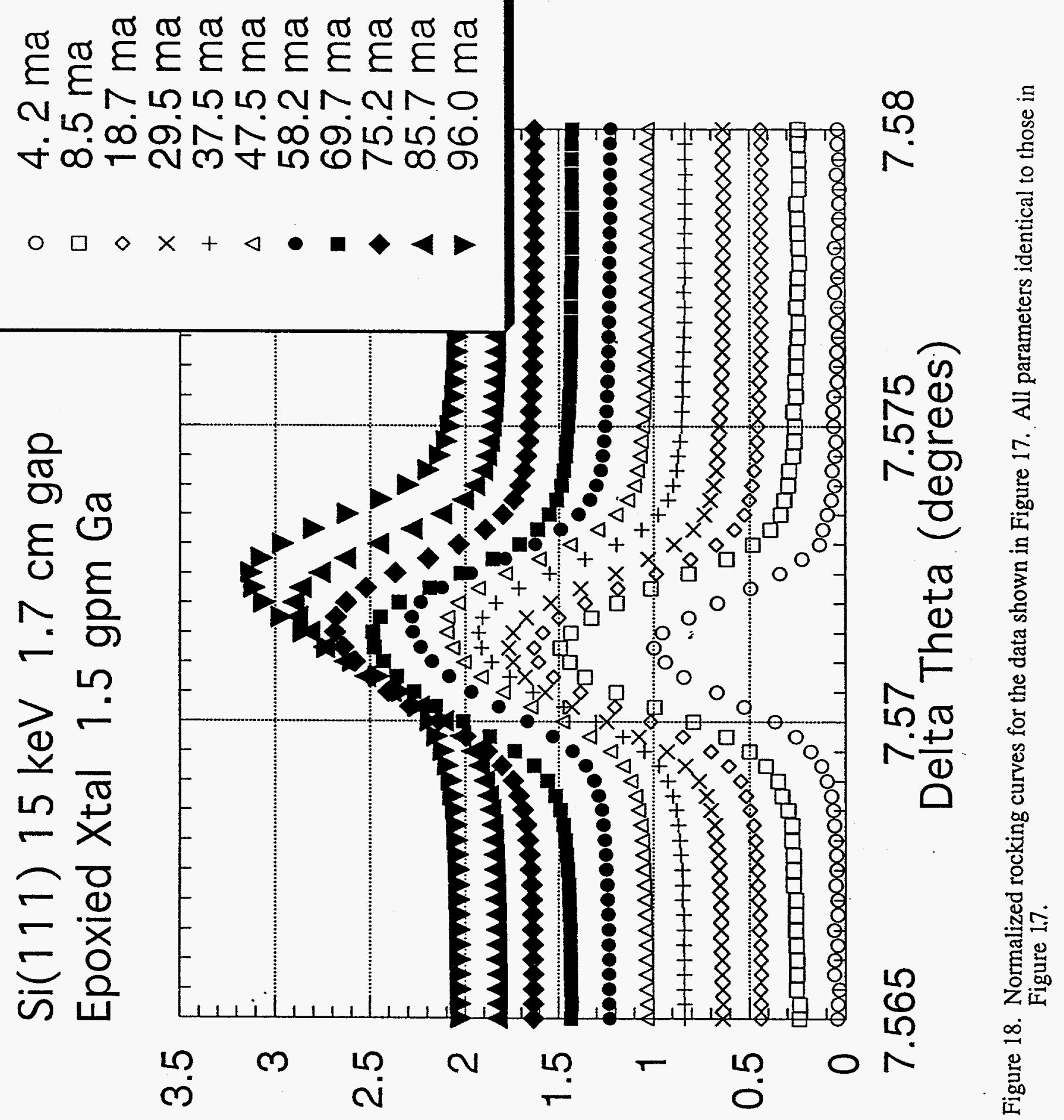

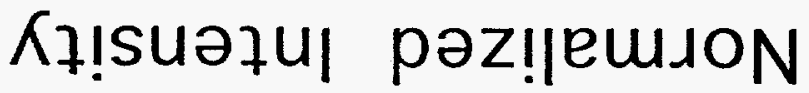




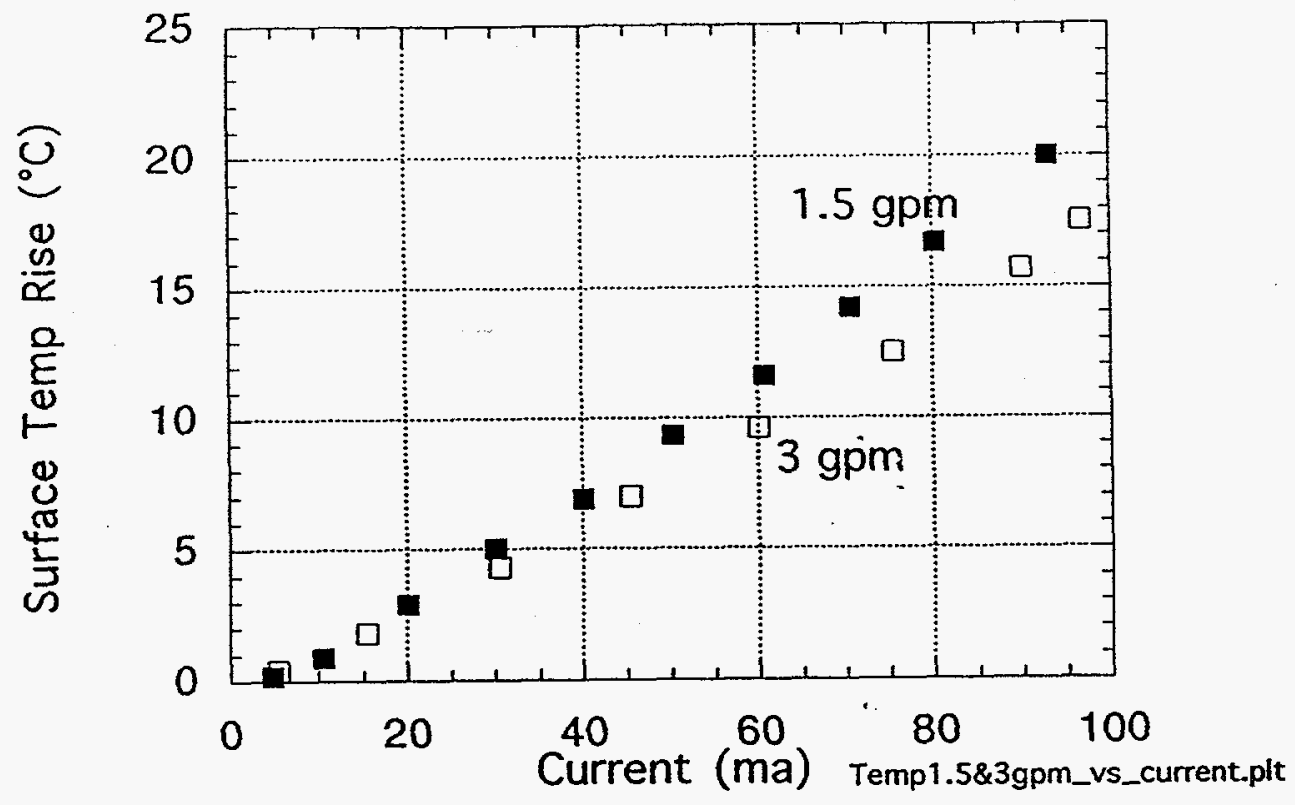

Figure 19. The surface temperature rise is plotted as a function of the stored beam current for the epoxy-bonded crystal at $1.5 \mathrm{gpm}$ (solid data points) and $3.0 \mathrm{gpm}$ (open data points). The plotted temperature rise is taken directly from an infrared camera observing the crystal and has not been corrected for the emissivity and transmissivity of the silicon crystal. 


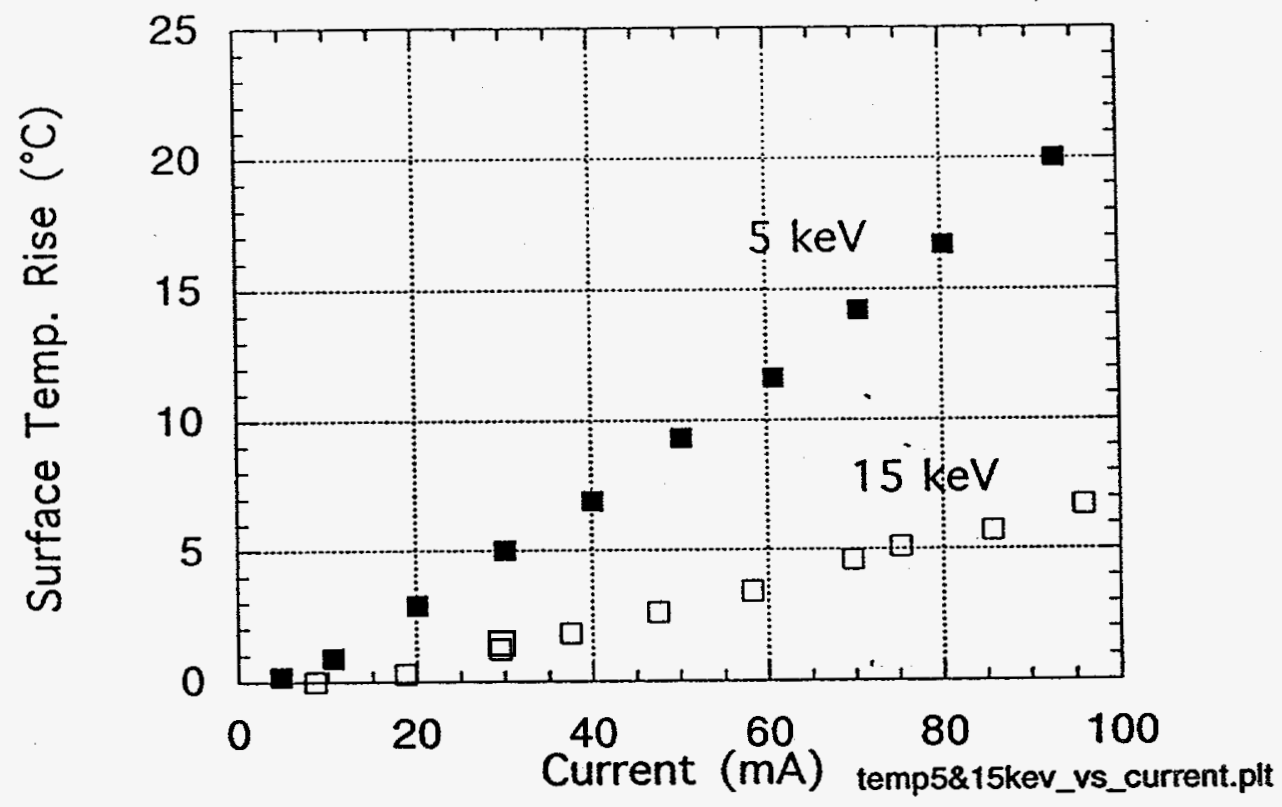

Figure 20. The surface temperature rise is plotted as a function of the stored beam current for the epoxy-bonded crystal at $5 \mathrm{keV}$ (solid data points) and $15 \mathrm{keV}$ (open data points). The plotted temperature rise is taken directly from an infrared camera observing the crystal and has not been corrected for the emissivity and transmissivity of the silicon crystal. 


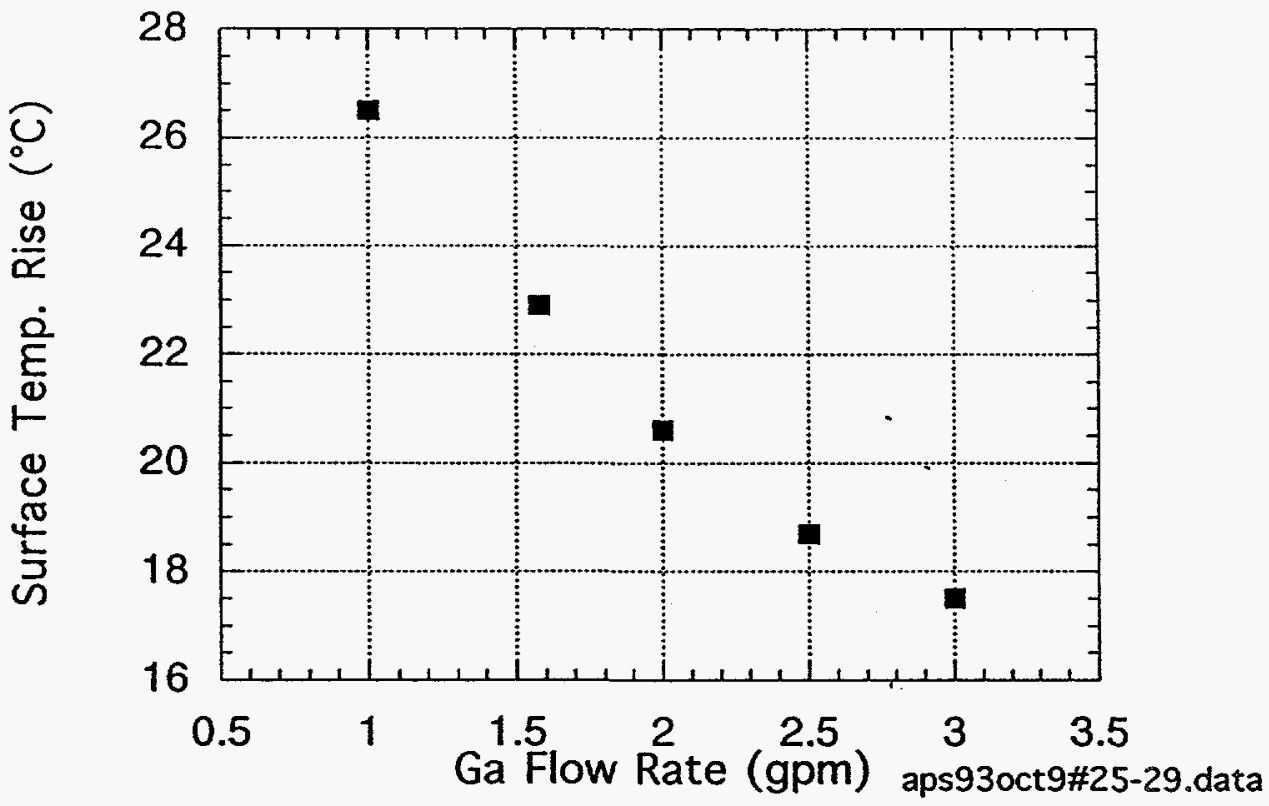

Figure 21. The surface temperature rise is plotted as a function of gallium flow rate for the epoxy-bonded crystal. Data were collected at a Bragg angle corresponding to $5 \mathrm{keV}$ for $\mathrm{Si}(111)$ planes and with a stored beam current near 100 milliamperes. 

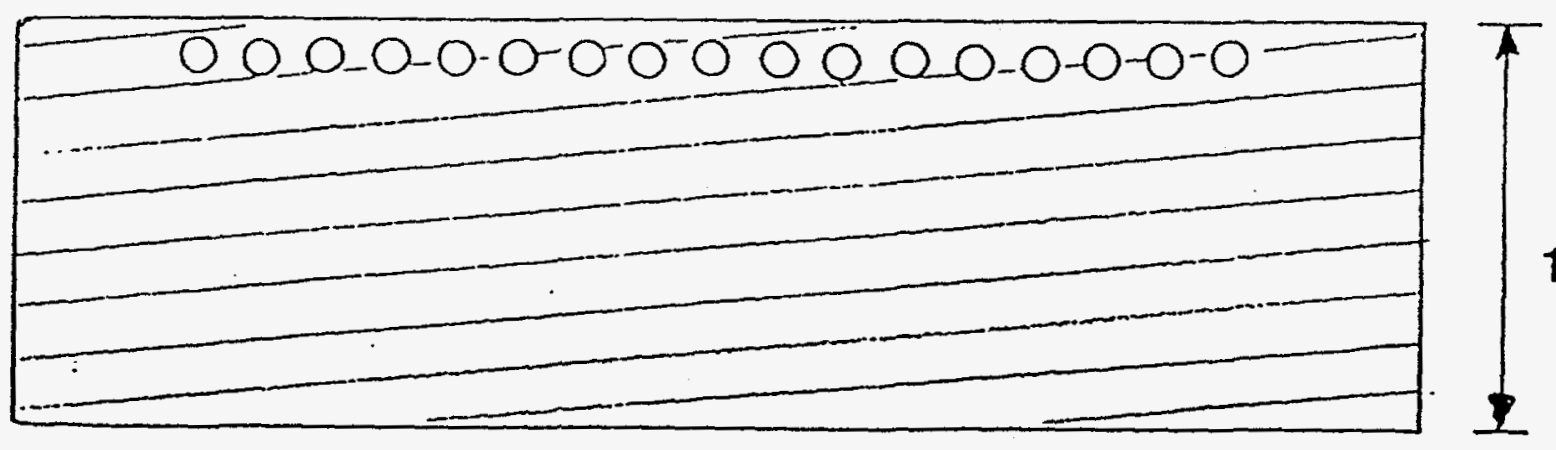

$14.2 \mathrm{~mm}$

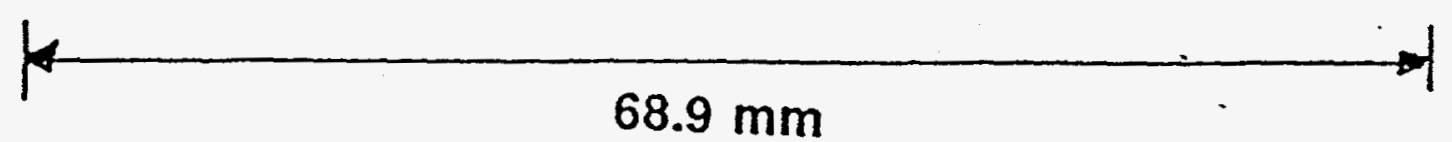

$14.2 \mathrm{~mm}$<smiles>[Y][Te]</smiles>

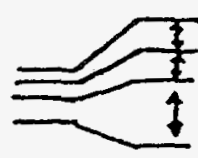
$.60 \mathrm{~mm}$

\section{$14.2 \mathrm{~mm}$}

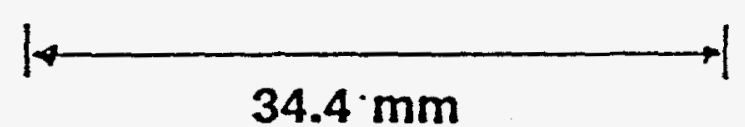

Figure 22. Diagram of the asymmetrically cut, core-drilled crystal. The channels in this crystal lie perpendicular to the diffraction plane. This was done for two reasons: 1) it is difficult to core drill 1.6- mm diameter holes almost $70 \mathrm{~mm}$ deep and 2) the manifold to seal the core-drilled holes can shadow the beam if the holes are drilled so that they are in the plane of diffraction. The surface of the crystal is cut $5^{\circ}$ from the (111) planes, and hole spacing was $3.2 \mathrm{~mm}$. 


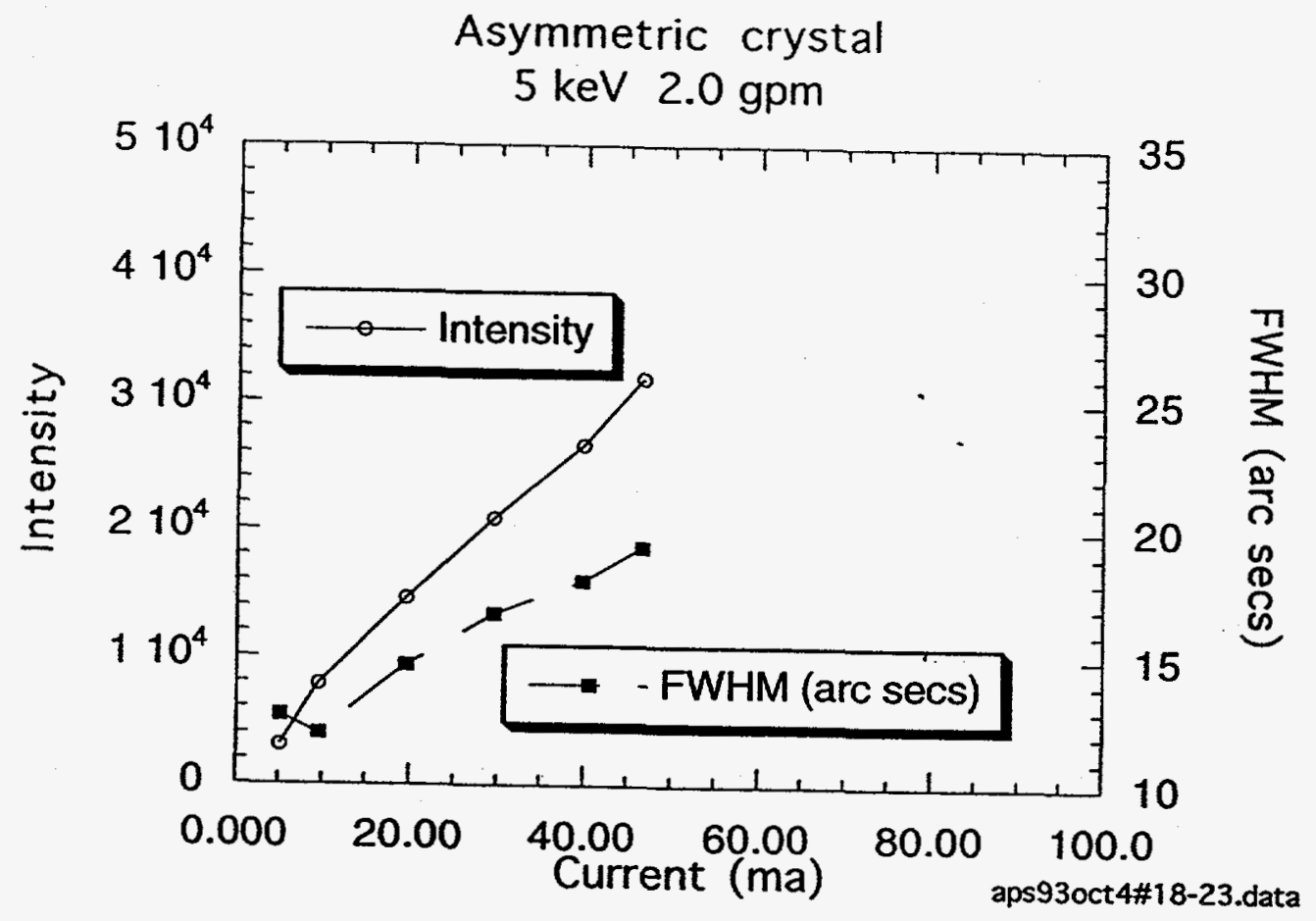

Figure 23. Plot of the intensity and FWHM of the asymmetrically cut Si (111) rocking curve as a function of stored beam current for the core-drilled crystal. (The normal incidence power density is about 25 watts $/ \mathrm{mm}^{2}$ at $100 \mathrm{~mA}$.) Data were collected at $5 \mathrm{keV}$ with a $2 \mathrm{gpm}$ gallium flow rate. 


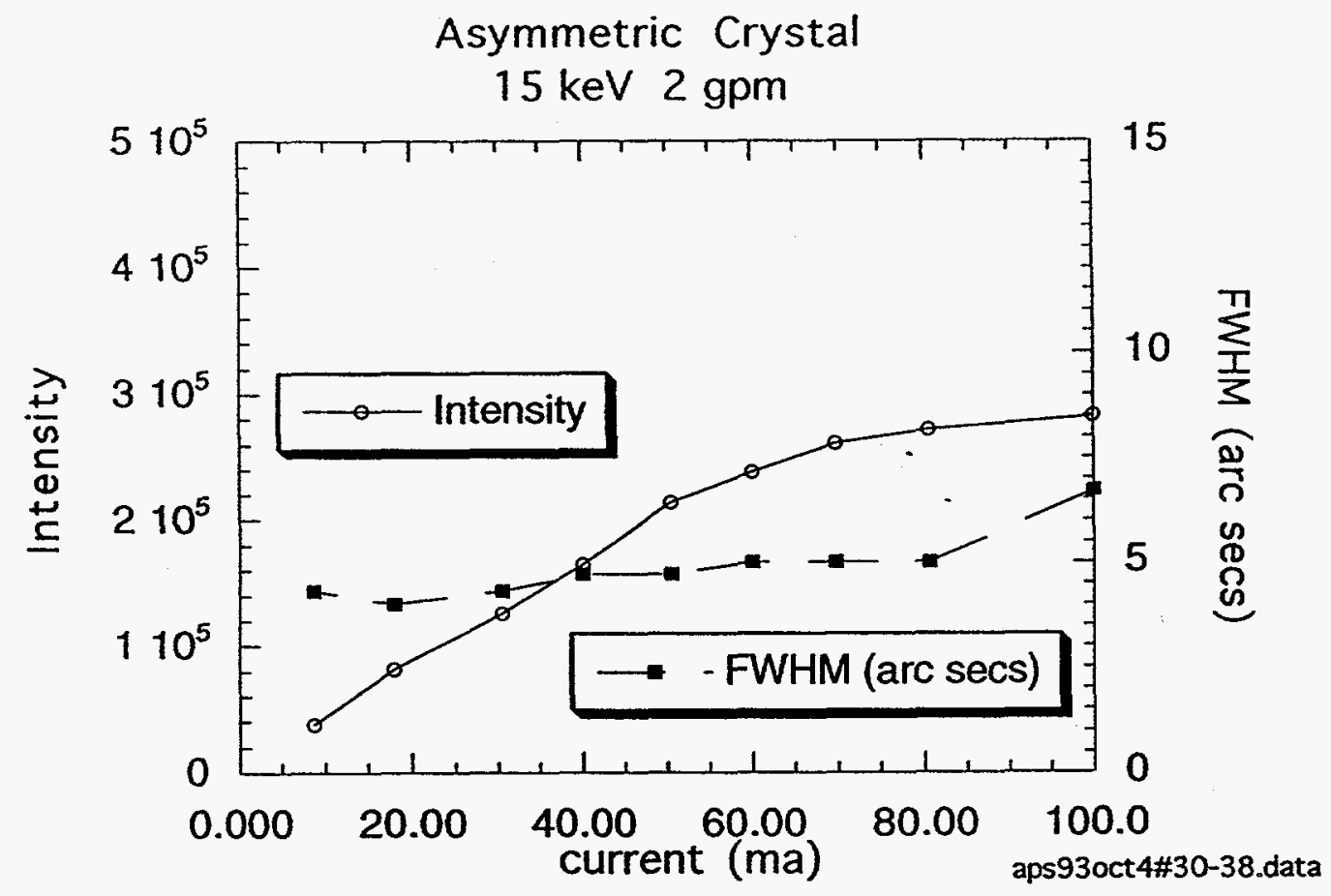

Figure 24 Plot of the intensity and FWHM of the asymmetrically cut $\mathrm{Si}$ (111) rocking curve as a function of stored beam current for the core-drilled crystal. (The normal incidence power density is about 25 watts $/ \mathrm{mm}^{2}$ at $100 \mathrm{~mA}$.) Data were collected at $15 \mathrm{keV}$ with a $2 \mathrm{gpm}$ gallium flow rate. 


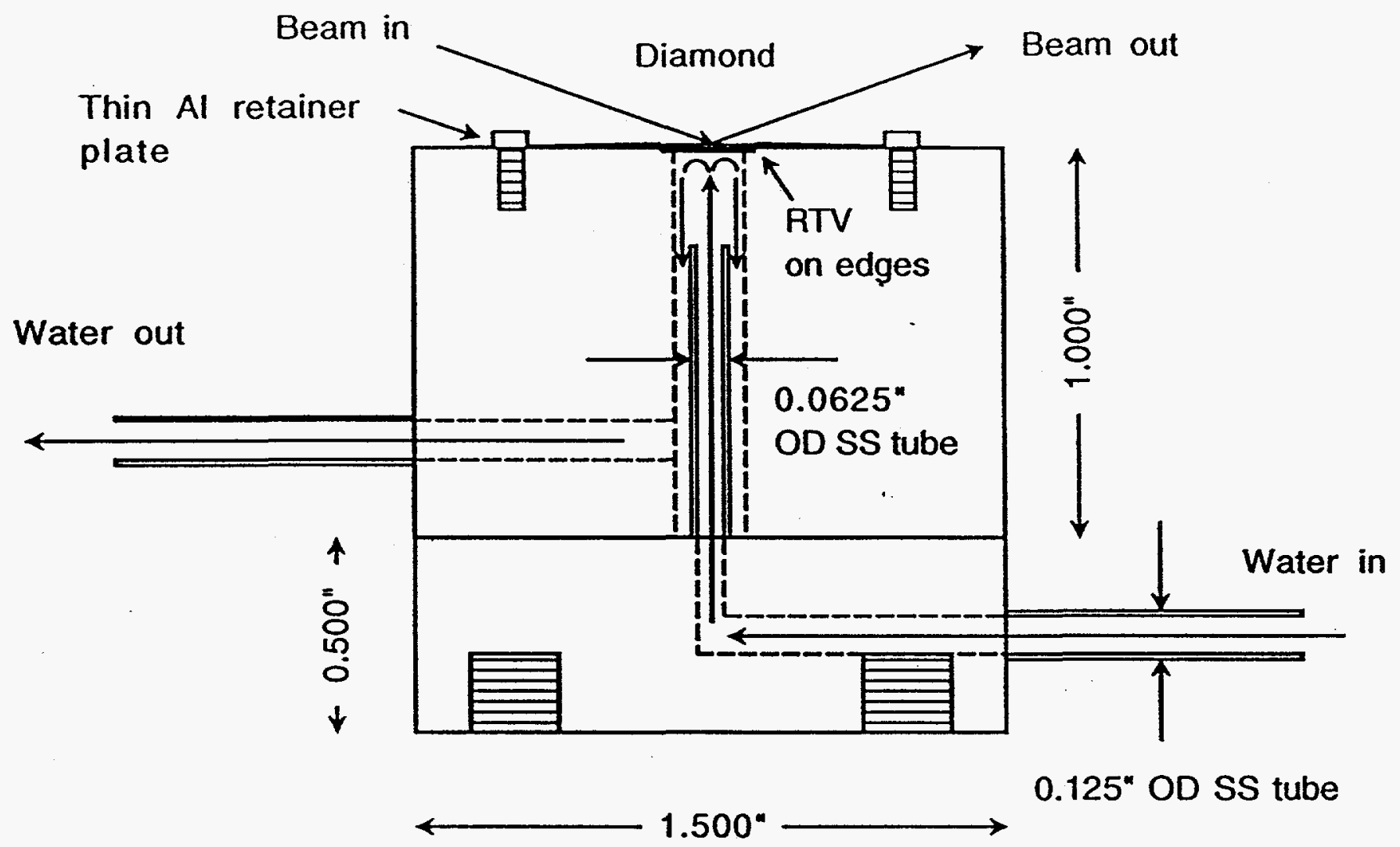

Figure 25. Drawing of the jet-cooled diamond and mount. 
10 FWHM (arc seconds)

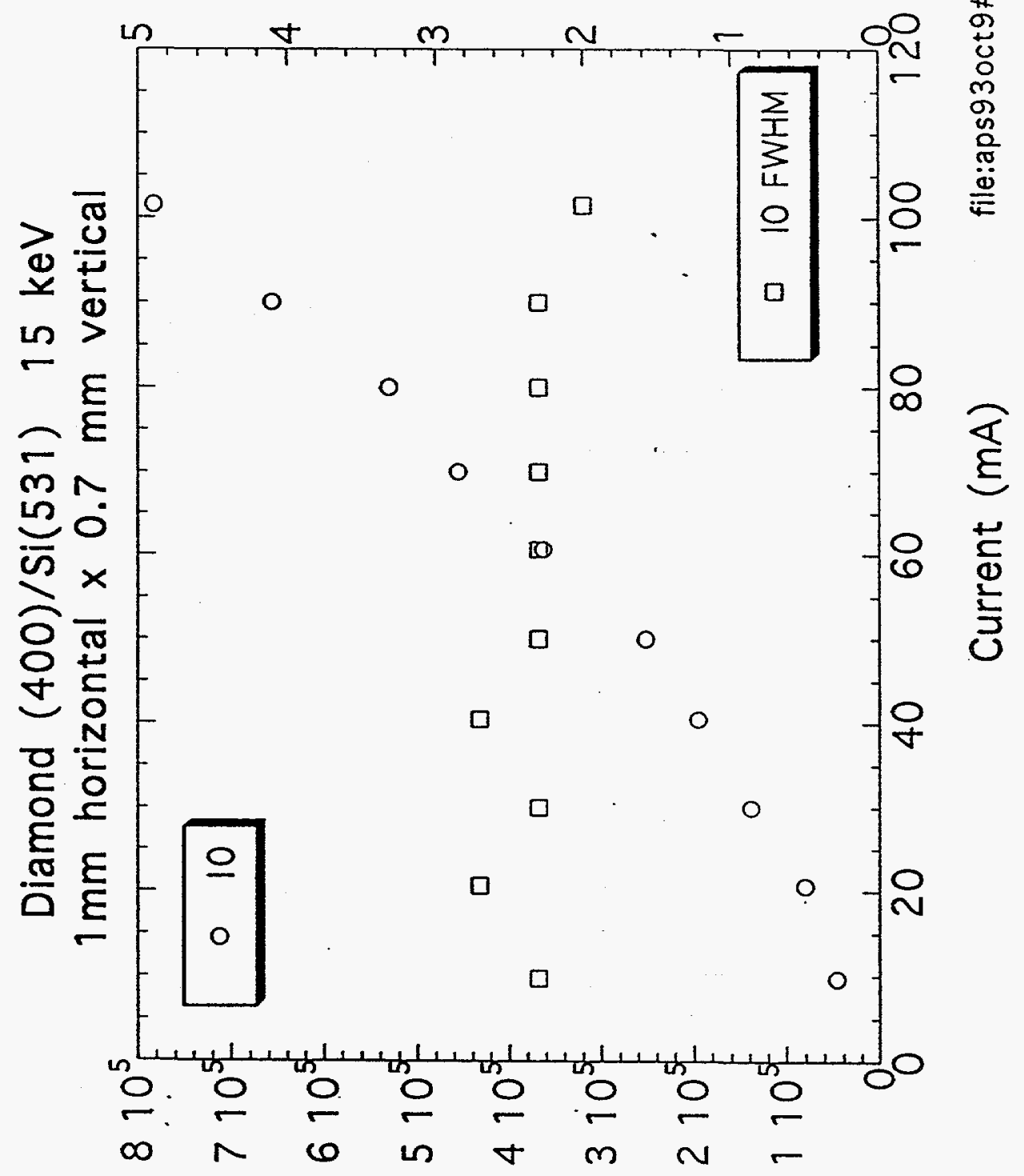

(sd3) Kұ!suәłu| 이

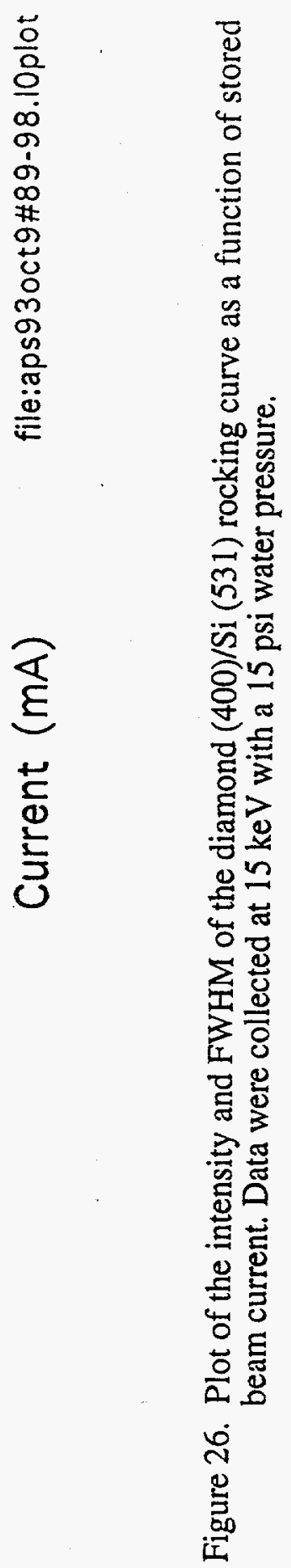




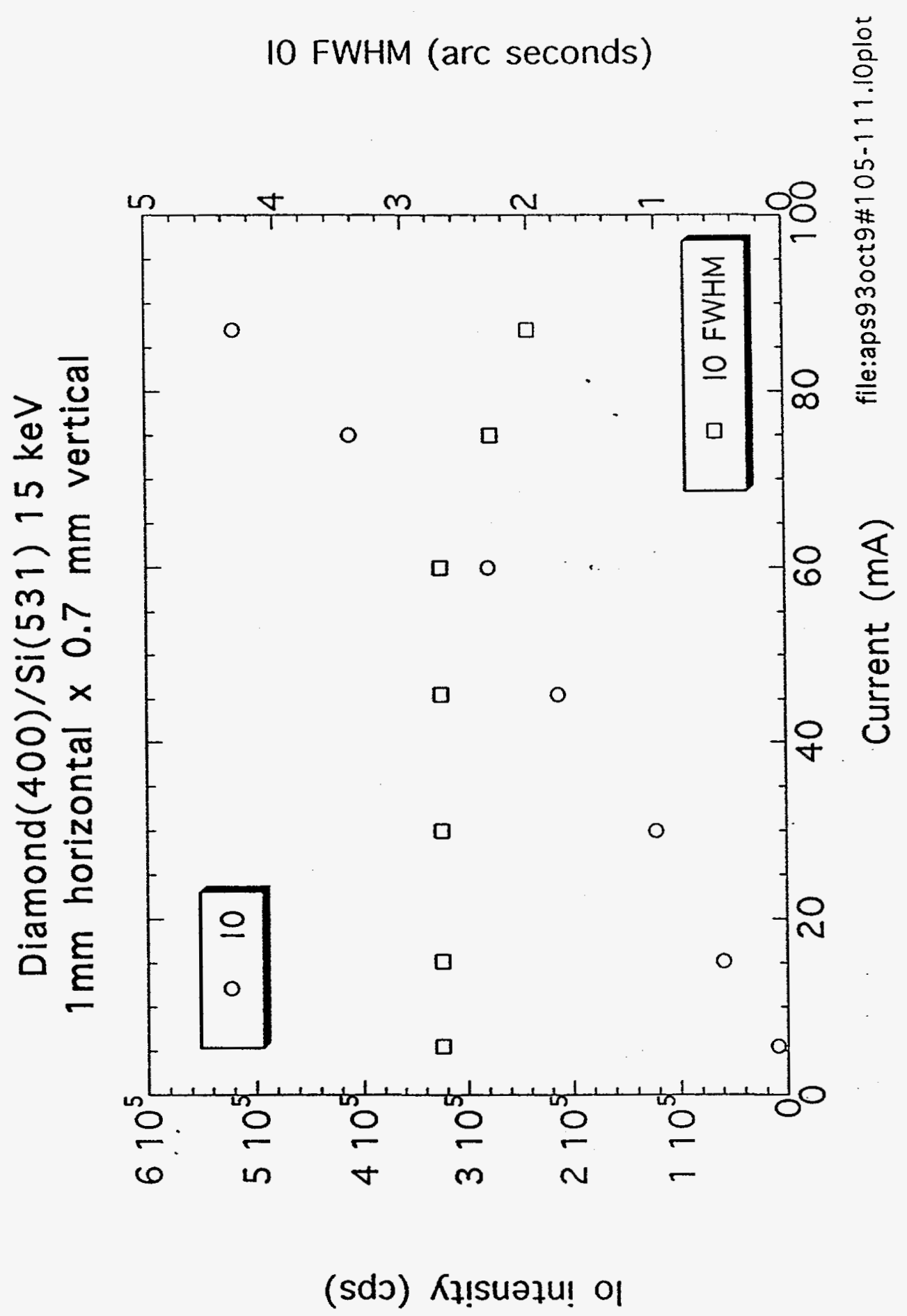

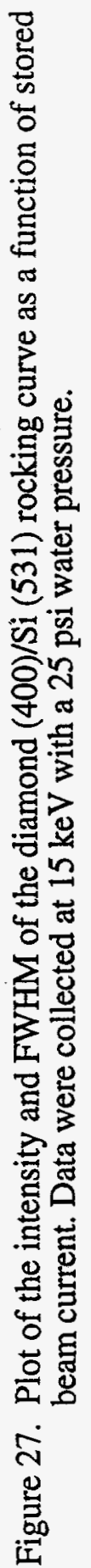


- 10

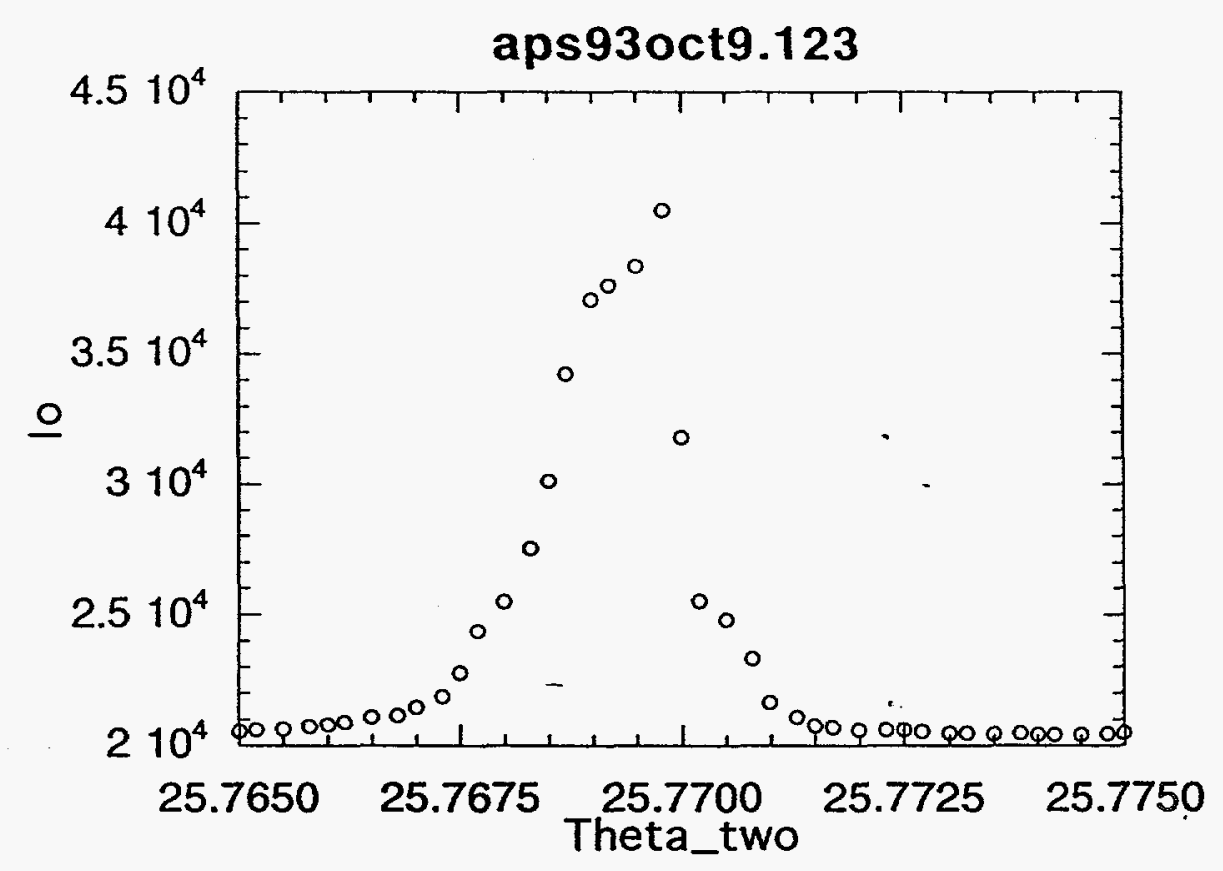

Figure 28. Rocking curve of the diamond (400)/Si (531) combination taken at $15 \mathrm{keV}$ with 4 milliamperes of current in the storage ring. 


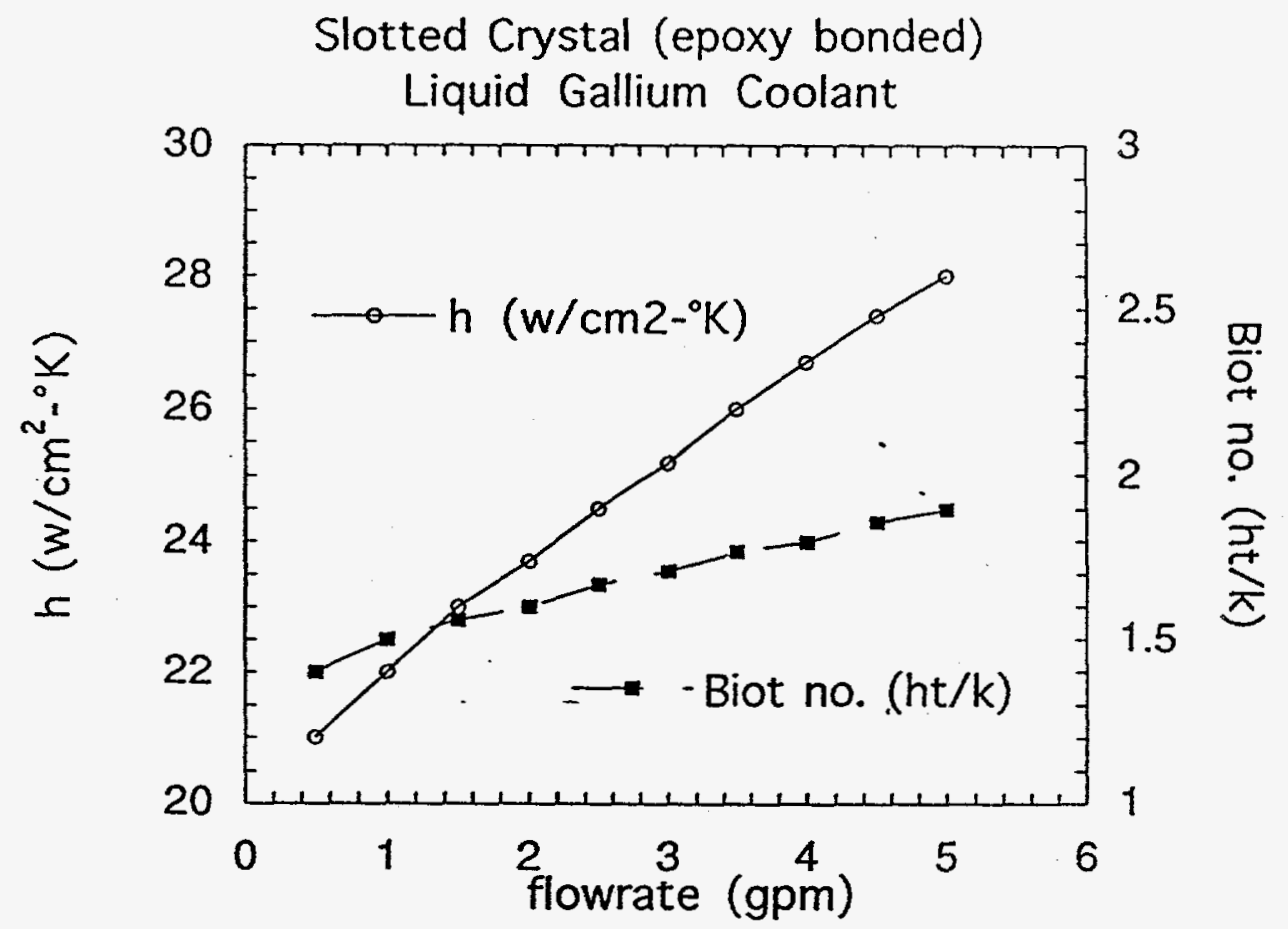

Figure 29. Heat transfer coefficient $(\mathrm{h})$ and Biot number $(\mathrm{ht} / \mathrm{k})$ are plotted as a function of gallium flow rate for the epoxy-bonded slotted crystal. 